\title{
ORDENACIÓN DEL USO PÚBLICO DE UN ESPACIO NATURAL PROTEGIDO EN UN DESTINO TURÍSTICO DE MASAS: LAS LAGUNAS DE TORREVIEJA Y LA MATA ${ }^{1}$
}

\author{
María Paz Such Climent \\ Departamento de Análisis Geográfico Regional \\ Universidad de Alicante
}

\section{RESUMEN}

Este artículo se enmarca en el tema de las relaciones entre turismo y medio ambiente, en el contexto de las estrategias de renovación-reestructuración planteadas en un destino turístico consolidado como es el municipio de Torrevieja, principal núcleo turístico de la zona suralicantina y uno de los más importantes de la Comunidad Valenciana. En particular, se exponen algunas de las iniciativas promovidas por la administración local, en relación con la ordenación del uso público del Parque Natural de las Lagunas de Torrevieja y La Mata. A propósito de este ejemplo, se previene acerca de la necesidad de adoptar criterios más amplios de ordenación territorial, respecto a un mejor aprovechamiento de las oportunidades que ofrecen los espacios naturales protegidos, en la cualificación de la oferta turística. torial.

Palabras clave: turismo, espacios naturales protegidos, uso público, ordenación terri-

\begin{abstract}
The content of this paper lies within the framework of the relations between tourism and environment in the context of the reform and restructuring of tourism strategies planned in Torrevieja, a consolidated tourist resort. This town is the main tourist destination of the south of Alicante and one of the most important in the Valencian Community.In particular, some of the local government initiatives regarding land use planning for public use of the La Mata and Torrevieja Lagoons Natural Park are explained. This example shows that it is necessary to take into account wider land use planning appro-
\end{abstract}

1 El presente artículo se inscribe en el marco del proyecto de investigación Planificación y gestión sostenible del turismo: Propuesta metodológica y aplicación de un Sistema de Información Turística (META$S I G)$, con referencia IFD97-0403, financiado por la Comisión Interministerial de Ciencia y Tecnología (CICYT) y la Comisión Europea (FEDER), que se desarrolla en la Universidad de Alicante, con participación de investigadores de las Universidades de Santiago de Compostela y Almería y del CSIC. 
aches to make the most of the protected natural areas and in order to improve the quality of the tourist services offered.

Key words: tourism, natural park, public use, land use planning.

\section{Introducción}

El convencimiento de que la conservación del medio ambiente se revela como la mejor garantía del mantenimiento de la actividad turística, ha favorecido que algunos destinos confieran una mayor atención al medio y a sus recursos, en sus actuales estrategias de reestructuración. En cierto modo, estas nuevas actitudes tienen su explicación en la crisis que afectó, a finales de los años ochenta, a los destinos maduros de sol y playa mediterráneos, la cual apercibía de los inconvenientes de una oferta indiferenciada y estandarizada, así como de la pérdida de competitividad asociada al deterioro ambiental, en relación con la mayor sensibilidad de la opinión pública, acerca de la necesidad de conservar el medio ambiente.

En este contexto, tomando como punto de partida los cambios en la demanda y la identificación del destino, en cuanto espacio de producción y consumo, con el producto turístico, las estrategias de reestructuración y renovación de los espacios turísticos han contribuido a replantear, a la vez que revalorizar, el papel de los elementos del medio geográfico como factores de desarrollo turístico. Estos objetivos han dado paso a actuaciones dirigidas a mejorar el estado de conservación del patrimonio natural y cultural pero, también, a iniciativas orientadas a explotar la potencialidad turística de recursos, hasta el momento mal o insuficientemente aprovechados. En particular, entre estas últimas destacan las estrategias de reestructuración basadas en la diferenciación y diversificación de la oferta, orientadas a satisfacer las tendencias de la demanda, manifiestas a lo largo del último decenio, en relación con los cambios operados en sus hábitos vacacionales, de compra y de consumo (GOYTIA, 1998).

Las dos líneas de intervención señaladas ponen el acento en la idea de aprovechar el territorio como recurso y no como mero soporte (VERA y MONFORT, 1994:35), bien a partir del diseño de nuevos productos basados en elementos singulares que fundamentan la diferenciación de la oferta local, bien de la incorporación de nuevos atractivos que contribuyen a diversificar la oferta convencional de sol y playa (VERA,1997: 104). En lo que atañe a la diversificación, las acciones emprendidas han consistido principalmente en la creación de oferta complementaria con la construcción de puertos deportivos y campos de golf, pero también se plantean otras opciones con la puesta en valor de recursos del medio natural y cultural, que pueden propiciar nuevas prácticas recreativas y el diseño de productos más específicos y originales, en los destinos tradicionales de sol y playa. En esta línea, se puede decir que los elementos del medio natural y cultural, y sus potencialidades recreativo-turísticas, ofrecen unas amplias e interesantes posibilidades para satisfacer las tendencias actuales de la demanda relativas a una mayor participación activa, exigencia de calidad ambiental, contacto con la naturaleza y diversificación motivacional ${ }^{2}$.

Las ideas expuestas cobran una gran trascendencia en los destinos de sol y playa maduros del litoral valenciano que, orientados al turismo de masas, revelan importantes signos de agotamiento. En ellos se impone como prioridad la necesidad de redefinir el

2 Véase, por ejemplo, el trabajo «Espacios Naturales Protegidos y desarrollo turístico en el litoral mediterráneo», presentado por Blázquez Salom y Vera Rebollo en las V Jornadas de Economía Mediterránea, organizadas por la Cámara Oficial de Comercio de Murcia, y publicado en BUENDÍA AZORÍN, J.D. y COLINO SUEIRAS, J. (Edts.) (2001): Turismo y Medio Ambiente. Cívitas. Madrid. pp. 69-104. 


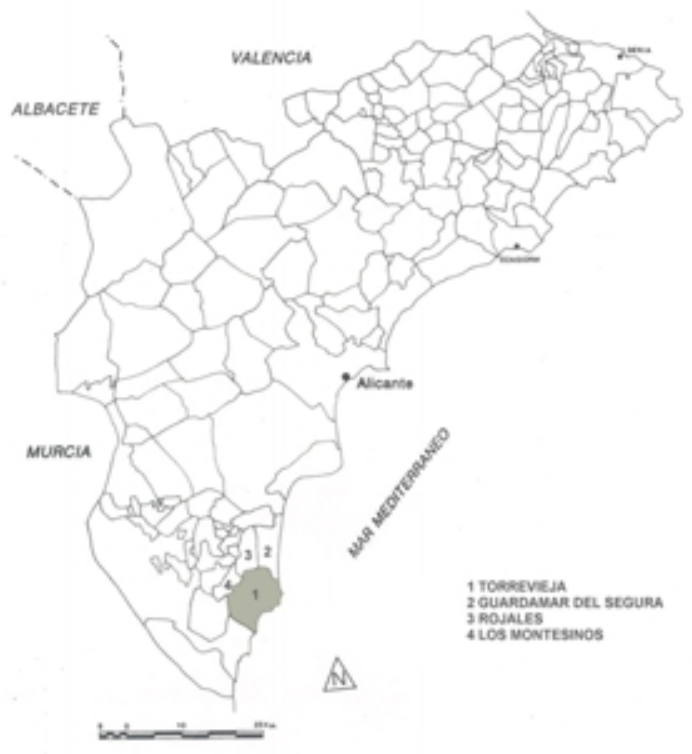

MAPA N ${ }^{\circ}$ 1: Localización de la zona de estudio.

modelo de desarrollo turístico desde las premisas de su sostenibilidad, y emprender acciones dirigidas a incorporar nuevos elementos a la oferta, con el fin de cualificar y diversificar el producto, frente a las habituales lógicas de crecimiento continuado. Con el propósito de ilustrar algunas de las opciones que se pueden insertar en este proceso, exponemos algunas de las iniciativas planteadas desde la administración local en el municipio alicantino de Torrevieja, en relación con la ordenación del uso público de un espacio natural protegido (vid. mapa $\mathrm{n}^{\mathrm{o}} 1$ de localización).

\section{Las Lagunas de Torrevieja-La Mata: consideración de la relación turismo-medio ambiente en un espacio natural protegido de gran valor ambiental, sometido a una fuerte presión antrópica}

El espacio natural protegido, objeto de nuestra atención, está formado por una depresión endorreica, contigua a la costa y ocupada por dos lagunas, extendiéndose entre los municipios de Torrevieja, Guardamar del Segura y Los Montesinos. Exactamente, esta zona húmeda que se integra en el conjunto de los espacios naturales protegidos de la Comunidad Valenciana con la categoría de parque natural, abarca un área de 3.754,8 Ha, de la cual $1.400 \mathrm{Ha}$ corresponden a la laguna de Torrevieja y $700 \mathrm{Ha}$ a la laguna de La Mata. Ambas lagunas se encuentran comprendidas en su totalidad en el municipio de Torrevieja, suponiendo el 28,25\% de la superficie de su término municipal, porcentaje que se eleva a un $35 \%$ si se incluyen sus respectivas redondas - nombre con el que se identifican los espacios circundantes aledaños, asociados a las fluctuaciones del régimen hídrico-e, incluso, al 50,32 \% si se considera todo el ámbito del parque natural, ya que el $96 \%$ del mismo se encuentra en este municipio.

La singularidad geográfica y la importancia ecológica de la diversidad botánica y faunística que albergan dichas lagunas y su entorno inmediato, en especial, como hábitat 
de una variada avifauna, con más de un centenar de especies que utilizan sus diferentes ambientes bien como áreas de descanso en sus migraciones anuales, bien como áreas de invernada y nidificación, justifican plenamente la necesidad de conservar esta zona húmeda y la serie de figuras de protección que recaen sobre ella, con tal fin (vid. tabla $\mathrm{n}^{\circ} 1$ ). Para la ornitofauna es particularmente valiosa la laguna de La Mata, convertida en Refugio Nacional de Caza (Decreto 74/1988, de 23 de mayo del Consell), de manera que a las especies habituales se añaden gran número de aves acuáticas, cuando se levanta la veda en los espacios húmedos aledaños. Entre las aves más habituales destaca la población de zampullín cuellinegro durante el invierno, la comunidad de flamencos que aprovechan la laguna de La Mata como área de reposo y alimentación durante sus migraciones y, como especies nidificantes, el tarro blanco y el aguilucho cenizo. La presencia de esta última es de gran valor, ya que sólo mantiene otra colonia en la Comunidad Valenciana, precisamente en otro espacio natural protegido, el Parque Natural del Prat de Cabanes-Torreblanca en el litoral castellonense.

Tabla $\mathrm{n}^{\mathrm{o}} 1$

AVES DEL PARQUE NATURAL DE LAS LAGUNAS DE LA MATA Y TORREVIEJA

\begin{tabular}{|c|c|c|c|}
\hline $\begin{array}{c}\text { NIDIFICANTES } \\
\text { (Sedentarias y estivales) }\end{array}$ & $\begin{array}{c}\text { SEDENTARIAS NO } \\
\text { NIDIFICANTES }\end{array}$ & INVERNANTES & MIGRATORIAS \\
\hline 61 & 3 & 44 & 12 \\
\hline
\end{tabular}

Fuente: De la Vega, A. (Coord.) (2000): Guía Práctica de Aves del Parque Natural de las lagunas de La Mata y Torrevieja. Ayuntamiento de Torrevieja. Alicante. Elaboración propia.

A su función de espacio vital para las aves se suma la importante masa vegetal que coloniza esta zona, acogiendo una excelente representación de comunidades hidrófilas y halófilas que constituyen hábitats naturales de interés comunitario, contemplados en la D97/62/CE, por la que se adapta al progreso científico y técnico la D92/43/CEE, relativa a la conservación de los hábitats naturales y de la flora y fauna silvestres, en concreto un total de ocho, algunos de los cuales de carácter prioritario (lagunas y estepas salinas mediterráneas). Estas comunidades vegetales se disponen en vistosos conjuntos formados por carrizales, juncales y saladares, que se desarrollan, según las condiciones edáficas de humedad y salinidad. De interés particular es la presencia, entre las comunidades halófilas, de endemismos del sureste peninsular, como son el Limonium caesium y la Salsola genistoides. Pero si este elevado valor ecológico ya fundamenta por sí solo su conservación, no es su único rasgo a destacar, pues hay que sumarle su enorme interés paisajístico resultante de la presencia de las láminas de agua y de los citados poblamientos vegetales, factores que confieren una alta calidad visual intrínseca al paraje.

Como se advierte en otros muchos casos, las cualidades apuntadas no implican que se trate de un espacio natural en sentido estricto, ya que se tiene constancia de la intervención del hombre desde la Edad Media, época en la que se lleva a cabo la comunicación de la laguna de Torrevieja con el mar con el fin de explotar la pesca. Abandonada esta empresa por los malos resultados, su aprovechamiento salinero ha sido realmente crucial en su configuración actual, al garantizar una inundación continuada y, en definitiva, el mantenimiento de su condición de zona húmeda. Ambas lagunas y sus respectivas redondas son propiedad estatal de carácter patrimonial y, por tanto, su gestión corresponde al Patrimonio del Estado que la mantiene arrendada a una compañía particular para su aprovechamiento salinero, desde 1870, aunque su explotación regular data de principios de ese siglo. Preci- 
samente coincidiendo con la renovación del contrato de arrendamiento, realizada en 1990, a la actual arrendataria, la Nueva Compañía Arrendataria de las Salinas de Torrevieja del grupo Union $\mathrm{Sal}^{3}$, en la misma se incluyen determinadas cláusulas relativas al mantenimiento y uso de las salinas, por las que dicha entidad queda obligada a su conservación sin introducir modificaciones que pudieran alterar su superficie o sus valores ecológico-paisajísticos e, incluso, se plantea su colaboración respecto a la posibilidad de realizar visitas organizadas. Por lo que respecta al sistema de explotación actual, la extracción de la sal tiene lugar en la laguna de Torrevieja tras la precipitación del cloruro sódico, a partir de las salmueras procedentes del diapiro salino de Pinoso, conducidas hasta la misma a través de un salmueroducto, mientras que la laguna de La Mata, comunicada con la anterior a través de un canal, se utiliza como calentador y para mantener en niveles óptimos la primera, si bien su papel en el proceso de producción ha disminuido desde la construcción de la citada conducción.

A la explotación salinera se suman otros usos tradicionales como la caza, principalmente de acuáticas, prohibida en la actualidad por su Plan Rector de Uso y Gestión (PRUG), la agricultura y el pastoreo en las redondas. A los efectos derivados de estas actividades más o menos compatibles con el cuidado del ecosistema (fluctuaciones del nivel del agua, extensión de cultivos sobre carrizales y saladares, sobrepastoreo, furtivismo, etc.), hay que añadir la fuerte presión antrópica asociada a la densa urbanización turístico-residencial implantada en sus márgenes y que engrosan la lista de impactos (vertidos incontrolados de escombros, basuras, baño en las lagunas, pisoteo y eliminación de la vegetación, incendios, etc.). La expansión de las urbanizaciones en su entorno, vía clasificación del suelo contenida en el planeamiento urbanístico, condicionada sólo por los lindes de la propiedad pública, ha ocasionado un importante uso público de este espacio natural protegido, tanto de la laguna de La Mata que hasta el momento ha servido además de soporte para las visitas guiadas, como de la laguna de Torrevieja, utilizada como zona de esparcimiento por la población residente aledaña.

En este contexto y a pesar de la ordenación y normativa de protección prevista en el planeamiento urbanístico general y demás afecciones jurídico-administrativas, el papel que se le ha reservado al paraje en el espacio turístico tanto de Torrevieja, como de los municipios de su área de influencia, se ha reducido, en la práctica, a su simple utilización como reclamo por parte de las distintas promotoras inmobiliarias actuantes en su entorno, atraídas por el menor precio del suelo respecto a otros espacios más próximos al mar y la rápida ocupación del frente costero. En este proceso, destaca un cambio en el tratamiento dispensado a este espacio, pasando de una indiferencia casi total en los primeros desarrollos urbanísticos, a su mayor valoración aprovechando su calidad visual como fondo escénico para cualificar las últimas promociones.

\section{Modelo de desarrollo turístico y costes ambientales asociados}

Turismo y medio ambiente se encuentran estrechamente relacionados en el litoral valenciano, y no se puede poner en duda el papel que los elementos del medio físico han jugado como soporte y fundamento de la actividad turística, aunque al margen de una planificación y ordenación de los espacios turísticos que asumiera la capacidad de acogida

3 Unión Sal cuenta con cuatro centros dedicados a la explotación salinera en España: Almería, Cádiz, Torrelavega y Torrevieja. La producción media de sal de las salinas de Torrevieja, mejorada desde la construcción del salmueroducto que aporta salmueras procedentes del diapiro salino de Pinoso, está en torno a las 750.000 toneladas, cantidad que representa aproximadamente el $80 \%$ de la producción de dicha empresa. 
y las limitaciones ambientales de los ecosistemas costeros. La falta de consideración de unos objetivos ambientales basados en la conservación de los recursos naturales, y de la excelencia del complejo físico-ecológico sobre el que se sustenta la actividad, ha reducido la creación del espacio turístico a un continuo proceso de ocupación del frente marítimo, sin prever la conveniente y necesaria protección de los sistemas ambientales de valor ecológico-paisajístico presentes en el mismo ${ }^{4}$. De esta manera, la proximidad al mar, como máxima de todas las actuaciones, ha conducido a reservar toda la fachada marítima a la urbanización turística como nota común a todos los desarrollos llevados a cabo. Por esta razón, el modelo territorial sujeto a la actividad turístico-residencial es, en gran medida, el responsable de la profunda transformación paisajística operada en el litoral valenciano, de la pérdida de hábitats naturales y, también, del estado lamentable de algunos de nuestros espacios naturales protegidos. Hecho que, por ejemplo, se puede comprobar en la Albufera de Valencia, El Montgó, las Salinas de Santa Pola y en las propias lagunas de Torrevieja y La Mata.

El municipio litoral de Torrevieja localizado en el extremo meridional de la Costa Blanca, no escapa a esta dinámica y, en particular, se incluye, en atención a la estructura de su sistema turístico, en la categoría de «vacacional intensivo», de acuerdo con la tipología propuesta en las Bases para la redacción del Plan Director de Espacios Turísticos de la Comunidad Valenciana, elaboradas por la Fundación Cavanilles de Altos Estudios Turísticos. Dicha categoría se caracteriza por una considerable oferta residencial que supone una importante ocupación de espacio y suelo, deterioro del paisaje y dispersión de las actuaciones con elevados costes en infraestructuras y despilfarro de recursos naturales. En este caso, la componente residencial se convierte en el elemento definidor de un modelo de desarrollo turístico basado en el crecimiento continuado de la oferta de viviendas de uso turístico, claramente incompatible con la calidad del entorno, el respeto del patrimonio natural y el mantenimiento de recursos con categoría de bienes ambientales (paisaje, suelo, agua, etc.), por su sobreexplotación y los problemas ambientales asociados — ruido, contaminación visual, erosión de playas, alteración y destrucción de hábitats naturales, producción de residuos sólidos urbanos, etc.- a la fuerte presión de uso impuesta por un incremento poblacional que multiplica por seis el número de habitantes, pasando de 100.000 a 600.000, durante la temporada alta.

Se entiende así que, en la actualidad, el municipio de Torrevieja disponga únicamente de tres pequeños tramos costeros, apenas 2,5 kilómetros de los catorce de su frente litoral, es decir el 16,45 \% de su longitud, sin urbanizar y clasificados como Suelos No Urbanizables Protegibles en su PGOU, mientras que en el resto, acantilados, dunas y playas han sido invadidas y destruidas, como bien se puede observar en el núcleo de La Mata, pequeño asentamiento tradicional de la población situado en el norte del término municipal, desbordado por la actividad turística. Pero, además, Torrevieja se ha puesto como ejemplo del proceso urbanizador del litoral meridional de la provincia (TORRES,1995:81-86), a tenor de la rápida ocupación del suelo y el vertiginoso crecimiento experimentado en el número de viviendas construidas, especialmente elevado en la segunda mitad de la década de los años ochenta, llegándose a construir 21.294, entre 1988 y 1990, por delante incluso de Valencia, la capital autonómica. A la vez, este protagonismo es sinónimo también de degradación inmobiliaria por la baja calidad de las edificaciones, a la que se añaden las deficiencias en la urbanización y la falta de zonas verdes.

4 A propósito de esta consideración basta citar, por ejemplo, los casos de otros tantos espacios de gran valor ambiental situados en el litoral valenciano como la Marjal de Peñíscola, la Sierra d'Irta, El Montgó, Sierra Helada, el Puig de la Llorença y Morros de Benitatxel, las dunas de los Arenales del Sol, las Salinas y el Cabo de Santa Pola, y las Dunas de Guardamar, todos ellos igualmente sometidos a una importante alteración antrópica. 
Lógicamente, este proceso de implantación turístico-residencial implica elevados costes ambientales y un reducido dinamismo económico por la fuerte estacionalidad y la moderada capacidad de gasto de la población veraneante, de manera que la repercusión en el empleo estable es muy modesta, al igual que en el aparato comercial y de servicios (VERA, 1996: 439-474). Aspectos, en suma, que ponen en tela de juicio su modelo de desarrollo y amenazan la propia continuidad de la actividad turística, urgiendo un replanteamiento que garantice su sostenibilidad. En este sentido, la conveniencia de captar otros segmentos de la demanda, no sólo de mayor poder adquisitivo sino también más interesados por el medio ambiente y, al mismo tiempo, con efectos desestacionalizadores, aconsejan además de mejorar la calidad ambiental del municipio en su conjunto y su imagen como destino, diseñar nuevas ofertas basadas en la recuperación y ordenación del uso público de los espacios naturales, buscando sinergias positivas entre la conservación y la actividad turística.

\subsection{La producción y ordenación del espacio turístico a través del planeamiento urbanís- tico: el municipio de Torrevieja como ejemplo}

A falta de planes específicos para la ordenación de la actividad turística, más allá del limitado alcance territorial que tuvo el régimen especial previsto en la Ley de Centros y Zonas de Interés Turístico Nacional y, el todavía menor, de los Planes de Ordenación de la Oferta Turística de carácter provincial, este proceso se ha materializado a través de un planeamiento urbanístico, permisivo, flexible y desarrollista, como único mecanismo de producción. En el caso particular del municipio de Torrevieja, el proceso de ocupación del suelo comienza en la década de los sesenta con la implantación de los primeros asentamientos en la costa, resultado de la formulación de 9 planes parciales anteriores a su primer plan general, cuya aprobación no se produce hasta 1973. La entrada en vigor de este último dará soporte a las actuaciones iniciadas con la clasificación de Suelo de Reserva Urbana Turística y Rústico de Interés Turístico, afectando la primera a toda la franja costera comprendida entre el mar y la carretera nacional, que discurre paralela a la misma, a muy escasa distancia y, la segunda, al resto del término municipal. Precisamente al amparo de las facilidades urbanísticas dispensadas en dicho documento, se levantan también en esas tempranas fechas las primeras urbanizaciones en la redonda de la Laguna de Torrevieja, favorecidas asimismo por la estructura de la propiedad agraria de gran tamaño y el bajo precio del suelo, lo que explica la gran extensión superficial de estos planes parciales (VERA, 1987:360). Tras esta primera etapa, el PGOU de 1986 consolida el modelo paralelo a la costa y da vía libre a la ocupación del espacio ceñido entre la citada carretera nacional y la CV-905 de Torrevieja a Crevillente, que atraviesa el espacio intermedio entre las lagunas de Torrevieja y La Mata (vid. mapa $\mathrm{n}^{\mathbf{0}} 2$ ). Al mismo tiempo, el plan quintuplicaba la superficie de Suelo Urbano respecto al precedente, con la inclusión de una Delimitación de Suelo Urbano aprobada el 18 de marzo de 1983, resultado de la firma de 12 convenios urbanísticos y la inclusión de otros doce enclaves rodeados de suelo urbano, justificándose esta última con el propósito de garantizar la obtención de sistemas generales (espacios libres y equipamientos). De esta forma, el $18 \%$ de la superficie del término municipal quedaba clasificada como Suelo Urbano, al que se añadía la correspondiente al Suelo Urbanizable, resultando en total un $29 \%$ del municipio comprometido con la actividad urbano-turística, que continúa extendiéndose en torno a las lagunas, tanto con la ampliación de nuevas fases en la urbanización de Los Balcones, en el borde occidental de la laguna de Torrevieja, como en el espacio comprendido entre esta última y la laguna de La Mata, donde se produce un fuerte desarrollo en la segunda mitad de los años ochenta 


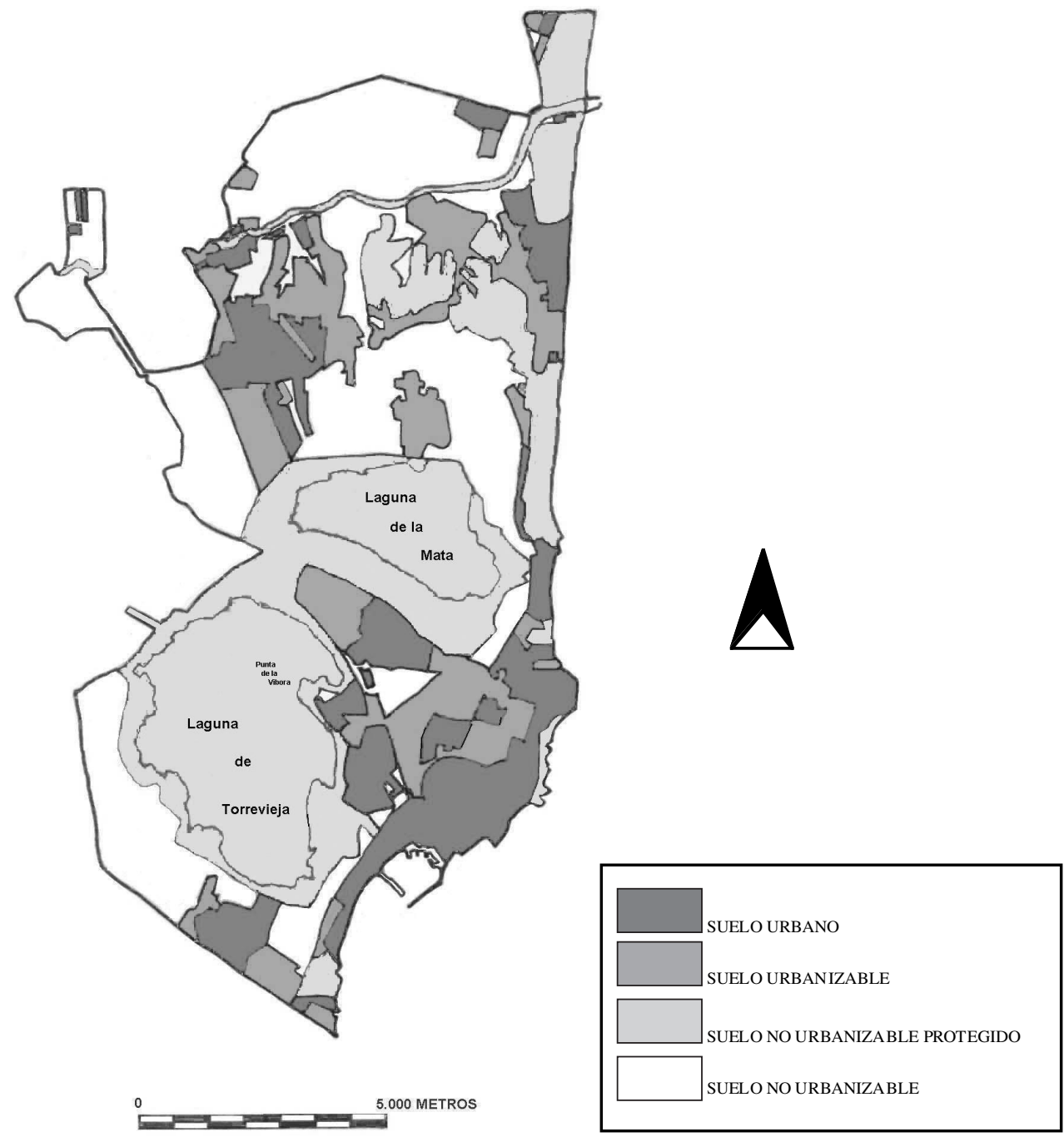

MAPA N $^{\circ}$ 2: Clasificación del suelo contenida en los documentos de planeamiento urbanístico de los municipios de la zona de estudio. Fuente: COPUT.

con la proliferación de adosados, que incrementan notablemente la densidad residencial. De la situación descrita se desprende también la fuerte presión que recae sobre el escaso suelo agrícola subsistente, reducido a una modesta porción que media entre la Laguna de La Mata y dicha pedanía y a la margen occidental de la laguna de Torrevieja, clasificado en ambos casos como Suelo No Urbanizable Común (SNUC) y, asimismo, sobre el propio Parque Natural que, aunque se incluye dentro del Suelo No Urbanizable Protegido (SNUP) quedando excluida la posibilidad de su urbanización, limita con zonas de Suelo Urbano y Urbanizable con alto grado de consolidación. Estas circunstancias revelan además la propia insostenibilidad del modelo de desarrollo del municipio, ya que las posibilidades de 
continuar con la expansión de las áreas residenciales se encuentran seriamente comprometidas ante la escasez de suelo y la obligada conservación del patrimonio natural.

\section{Tratamiento del Parque Natural de las lagunas de Torrevieja y La Mata en el planeamiento urbanístico municipal de Torrevieja y los municipios colindantes}

Como ya hemos expuesto, el municipio de Torrevieja es el más afectado por la existencia del parque natural, al quedar incluidas las dos lagunas y buena parte de sus redondas dentro de su término municipal. De los restantes municipios colindantes, sólo una pequeña parte del extremo nordeste del paraje se extiende hacia Guardamar del Segura $(2,90 \%)$ y otra, todavía menor, en el margen opuesto, hacia el de Los Montesinos $(1,10 \%)$, mientras que Rojales únicamente se encuentra afectado por el perímetro de protección de $500 \mathrm{~m}$ en torno al límite del espacio protegido, servidumbre que asimismo recae sobre los anteriores.

Revisados los diferentes documentos de planeamiento de estos municipios se advierte que, asumida la clasificación de SNUP para todo el parque natural, el problema, como ya hemos señalado, deviene de la inmediatez del suelo clasificado como SU, además de la existencia de varios sectores de Suelo Urbanizable a lo largo de las orillas de ambas lagunas e, incluso, de la insuficiente protección de la margen izquierda de la laguna de Torrevieja clasificada como SNUC. De esta forma a la ocupación actual de los bordes oriental (urbanizaciones El Chaparral y Torreta) y meridional de esta última (urbanización Los Balcones y Lago Jardín) y del derecho de la laguna de La Mata, se suman los desarrollos previstos de dos sectores en el borde septentrional de esta última, pertenecientes a los municipios de Guardamar del Segura y Rojales. Lógicamente todas las zonas delimitadas, así como los nuevos espacios a transformar, quedan sujetos al citado períme-

Tabla $n^{\circ} 2$

\begin{tabular}{|l|c|c|}
\hline & Superficie en Ha & \% \\
\hline S. Urbano & 124,8002 & 7,28 \\
\hline S. Urbanizable & 108,3603 & 6,32 \\
\hline S. No Urbanizable & 1479,2214 & 86,4 \\
\hline Total & 1712,3719 & 100 \\
\hline
\end{tabular}

Clasificación urbanística del suelo correspondiente al perímetro de protección establecido sobre una franja de 500 $\mathrm{m}$ de anchura, alrededor del Parque Natural de las Lagunas de Torrevieja y La Mata.

Tabla $n^{\circ} 3$

\begin{tabular}{|l|c|c|}
\hline & Superficie en Ha & \% \\
\hline S. Urbano & 495,5089 & 14,76 \\
\hline S. Urbanizable & 336,9019 & 10,03 \\
\hline S. No Urbanizable & 2523,4370 & 75,20 \\
\hline Total & 3355,8479 & 100 \\
\hline
\end{tabular}

Clasificación urbanística del suelo correspondiente a una franja de $1.000 \mathrm{~m}$ de anchura, alrededor del Parque Natural de las Lagunas de Torrevieja La Mata. 
tro de protección, aunque su estrechez, sumada a la propia delimitación del paraje realizada en su día, extremadamente ajustada a los lindes de la propiedad estatal, a los límites de los términos municipales y a la clasificación del suelo, resulta claramente insuficiente para salvaguardar los valores de esta zona húmeda. Sobre este particular, basta llamar la atención sobre la regularidad de dicho perímetro de protección, ya que su anchura, fijada de manera uniforme en $500 \mathrm{~m}$, difícilmente responde a los criterios geográficos, fisiográficos, ecológicos o funcionales en los que se debería basar su delimitación, según la Ley 11/1994, de Espacios Naturales Protegidos (LENP). Ante esta situación, la existencia del parque natural no ha impedido que hasta la actualidad se sigan urbanizando las parcelas aledañas, con el consiguiente incremento de la presión urbanística y poblacional sobre el mismo (vid. tablas $\mathrm{n}^{\circ} 2$ y 3 ). Estas actuaciones conllevan incluso la roturación de la vegetación natural y la ocupación por infraestructuras y viarios hasta los propios mojones del parque, anulando de hecho la función que el perímetro de protección habría de tener como área de amortiguación de impactos.

Por lo que respecta a Torrevieja, su PGOU de 1986 señala como criterios básicos de planeamiento la protección de los espacios de interés natural y el frenar la expansión desordenada del diseminado en las inmediaciones de las lagunas, con el fin de evitar el deterioro irreversible del medio natural y paisajístico. Pero a la par y, a modo de propuesta de diseño, dispone como única medida de ordenación para las áreas lindantes con las lagunas y entre ellas, la ocupación intensiva en baja altura para las zonas sin edificar con derechos adquiridos, sin propuesta alguna de carácter proteccionista.

No obstante, el citado PGOU concentra la protección del medio en dos enclaves a conservar: el litoral norte y el perímetro de las lagunas. A tal efecto, distingue varios ámbitos sujetos a distintos niveles de protección, incluyendo las lagunas, junto con la pinada de la Mata y las playas del término municipal, en la categoría de parque natural, sujeta a la máxima protección. Esta providencia se justifica, por lo que respecta al conjunto formado por las dos lagunas, en su calidad de zonas húmedas de alto valor ecológico, reconocido por el Fondo Mundial para la Vida Salvaje, con interés suficiente —a criterio de los redactores del plan- para su declaración como ENP, hecho que se produciría dos años más tarde. Según la normativa urbanística, la protección de estos enclaves debía atender fundamentalmente al mantenimiento o regeneración del ecosistema natural mediante planes prescriptivos, sin perjuicio de su disfrute y visita en tanto en cuanto fuera compatible. En particular, recomienda las siguientes medidas de protección para las lagunas: frenar el proceso edificatorio en las zonas colindantes hasta las carreteras circundantes, control estricto de la caza furtiva y repoblación del entorno con especies autóctonas. El plan incluye además el parque natural de La Mata y la zona interlagunar en el Sistema General de Espacios Libres, al mismo tiempo que recoge ambas lagunas y sus respectivas redondas, así como los pinares y la zona agrícola, junto a La Mata, en el catálogo municipal de elementos protegibles, anexo al PGOU, como elementos de interés científicoambiental y prohibición absoluta de la destrucción o reducción de su superficie, hecho que, según se expone, supondría una pérdida irreversible de recursos genéticos. Pero, como fácilmente se comprueba en la margen derecha de la laguna de Torrevieja, donde todavía se sigue construyendo, por lo que respecta al espacio que comprende las dos lagunas y que constituye en la actualidad el parque natural, las medidas de protección recomendadas no se han tenido en cuenta, excepto la relativa a la caza furtiva gracias a su condición de ENP y, en concreto, al plan de vigilancia asociado, mucho más efectivo desde la puesta en marcha de su PRUG, aprobado en 1995. De hecho, la expresa prohibición de la vivienda familiar de cualquier tipología arquitectónica, no impedía, tampoco, la posibilidad de edificación de vivienda unifamiliar aislada sobre parcela mínima de $5.000 \mathrm{~m}^{2}$, en un 
enclave colindante a la urbanización Los Balcones, en el extremo meridional de la laguna de Torrevieja, en atención a los derechos adquiridos con anterioridad a la vigencia del plan, cuya reclasificación como SU se solicitará más tarde, con ocasión de la Revisión del Programa de Actuación del PGOU.

Así pues, las consideraciones anteriores no han impedido en la práctica la consolidación de los planes parciales aprobados e, incluso, el desarrollo de otros nuevos, poniendo de relieve las manifiestas contradicciones e incoherencias en que incurre dicho documento de planeamiento. Su explicación es bien sencilla pues, en realidad, resultan una consecuencia del esfuerzo por asumir la situación urbanística heredada, respetar los derechos adquiridos y satisfacer las demandas de los promotores inmobiliarios y, al mismo tiempo, cumplir con el debido cuidado y mantenimiento del espacio natural, del que también es responsable la administración local, según el conjunto de atribuciones que le son asignadas en la Ley 7/1985, de Bases del Régimen Local — art. 25.2.f.—, si bien la implicación del Ayuntamiento, como representante del poder municipal, en la conservación y salvaguarda de este espacio fue, de hecho, nula. En cierto modo, esta situación se vio asimismo propiciada por la pertenencia del paraje al Patrimonio del Estado y la especial situación jurídica que recaía sobre las lagunas, sujetas a un contrato de arrendamiento a favor de la compañía encargada de explotar las salinas, funcionando en la práctica como una propiedad privada, sin dar lugar a cauces de colaboración entre la empresa y el Consistorio. Pero a ello se añade además la propia inercia impuesta por el modelo de desarrollo turístico imperante en esos momentos, claramente favorable al crecimiento de la oferta, potenciado por una política orientada especialmente a su fomento y, en menor medida, a su ordenación, la cual benefició a los intereses privados en sus desmedidos proyectos urbanísticos, al no encontrar ninguna resistencia en las corporaciones municipales. En este sentido, una evidencia más de esa tendencia continuista volcada a la producción de suelo residencial, fue la presentación de un Avance de Revisión del Programa de Actuación del PGOU, aprobado por el Ayuntamiento a finales de 1992, pero rechazado por el Servicio Territorial de Urbanismo de Alicante (STU) por el gran número de modificaciones sustanciales incluidas. En el mismo, aún sin encontrarse desarrollado todo el suelo urbano y urbanizable del primer cuatrienio, se incluían varias modificaciones puntuales que incrementaban el suelo residencial y suponían la reclasificación de más de 55 Ha de SNU. En concreto, se proponía la reclasificación directa de SNU a suelo urbano de dos enclaves, supuestamente consolidados, uno formado por $150.000 \mathrm{~m}^{2}$ de SNU en Los Balcones-Lago Sol y otro, como polígono urbano dotacional entre la CV-905 y la urbanización La Torreta, integrado en más de $90 \%$ por propiedad municipal. Asimismo proponía nuevos sectores de Suelo Urbanizable a costa del SNU, pero sin aportar el correspondiente estudio de impacto ambiental exigido por el artículo 2.2 de la Ley 4/1992, de SNU de la Comunidad Valenciana (LSNU). Entre ellos, se modificaba un sector de Suelo Urbanizable No Programado (SUNP) con uso de polígono industrial de las Salinas, para incorporarlo en parte a un nuevo sector de SUP residencial, operación que también implicaba la reclasificación de SNU de tolerancia industrial. Se creaban también el nuevo sector de SUNP Lomas de Polo en la zona de La Mata, junto al término municipal de Guardamar, que abarcaba $58.325 \mathrm{~m}^{2}$ de SNU, y el Sector El Limonar VI destinado a equipamiento público, sobre $90.000 \mathrm{~m}^{2}$ de SNU. A pesar de la devolución del expediente por el STU, el Ayuntamiento de Torrevieja volvió a remitir en 1995 un nuevo proyecto modificativo del Programa de Actuación, al que se adjuntaban veinticinco modificaciones, entre las cuales volvía a proponer la reclasificación de varios sectores en la Laguna de Torrevieja, junto a la urbanización Los Balcones (sectores 27 y 29) . Pero muestra de la voluntad y empeño por urbanizar esta zona fue,

5 Expte. 588/95. STU. COPUT. 
durante el año 2000, otro nuevo intento de aprobar un Plan Parcial modificativo del PGOU y expediente de homologación del sector 27, La Coronelita, promovido por la Altos de Edén, SA y localizado entre las urbanizaciones Los Balcones y El Lago y el nuevo trazado de la autopista Alicante-Cartagena. Esta pretendida actuación afectaba a una superficie de 23 Ha de SNU y proyectaba la construcción de mil viviendas sobre la cuenca vertiente de la laguna de Torrevieja ${ }^{6}$.

De igual manera, el PGOU de Guardamar del Segura que linda con las márgenes norte y noreste de la laguna de La Mata, también prevé el desarrollo del sector de Suelo Urbanizable El Raso colindante con esta última, fruto de un convenio urbanístico entre el Ayuntamiento y los propietarios de los terrenos. El citado convenio motivó la revisión parcial del PGOU, aprobada en 1990, y tenía como finalidad la reclasificación de SNU normal a Suelo Urbanizable, a cambio de 522 millones de pesetas destinados a la financiación de un puerto deportivo a construir en la desembocadura del río Segura, cuya inauguración se produjo en el año 1999. El Plan Parcial para el desarrollo del sector resultante de la operación comentada, fue aprobado el 4 de abril de 1995, tan sólo seis días antes de la entrada en vigor del $\mathrm{PRUG}^{7}$ del entonces paraje natural y, por tanto, sin obligación de someterse a estimación de impacto ambiental, tal como dispone el citado Plan Rector para los proyectos urbanísticos que afecten total o parcialmente al perímetro de protección. De esta manera, a tenor de dicho acto se autorizaba la urbanización de 122 Ha y la construcción de 3.091 viviendas con una altura máxima prevista de cuatro plantas, con reserva para 1.236 plazas hoteleras y 927 apartamentos, ocupando la franja de $500 \mathrm{~m}$ del perímetro de protección. No obstante su legalidad, el fuerte impacto ambiental de la urbanización sobre la laguna de La Mata y el incumplimiento de las obligaciones contraídas por los propietarios, motivó que los servicios territoriales de la Conselleria de Obras Públicas, Urbanismo y Transportes (COPUT) en Alicante, con ocasión de la emisión del informe preceptivo correspondiente al trámite de concierto previo de la revisión del citado plan general, iniciado en 1998, aconsejaran su desclasificación, o bien su reconsideración en cuanto a su delimitación por contravención de los criterios de sectorización contenidos en la Ley Reguladora de la Actividad Urbanística (LRAU), su ubicación y tamaño ${ }^{8}$. Desatendida esta petición y a pesar del acuerdo de 3 de noviembre de 1999, del Gobierno Valenciano, de adopción de medidas cautelares de protección en los espacios incluidos en el Catálogo de Zonas Húmedas en trámite de aprobación y, también, de la Orden de 1 de junio de 2000, de

6 En concreto, esta última estrategia motivó la presentación de una alegación por parte de la Asociación de Amigos de los Humedales del Sur de Alicante (AHSA), en la cual además de incidir en los perjudiciales efectos paisajísticos que tiene este proyecto, se ponía de relevancia la exclusión del sector afectado de la cuenca vertiente de la laguna, según la nueva delimitación propuesta en el Catálogo de Zonas Húmedas sometido, por segunda vez, a trámite de exposición pública en junio de 2000.

7 El PRUG de las Lagunas de Torrevieja y La Mata fue aprobado por el Decreto 49/1995, de 22 de marzo, del Gobierno Valenciano, pero su publicación en el DOGV se llevó a cabo el día 12 de abril, entrando en vigor al día siguiente.

8 Expediente (PL 980494/76). Teniendo en cuenta la clasificación de 1.254,21 Ha de Suelo Urbanizable con un incremento respecto del plan anterior de 664,70 Ha, la actuación comentada y otras más planteadas motivaron que el informe emitido, a efectos del concierto previo, cuestionara el modelo territorial propuesto en el proyecto presentado. En este sentido, la resolución del Subsecretario de Urbanismo y Ordenación del Territorio señalaba que «El modelo de crecimiento planteado por el Ayuntamiento para el municipio, no resulta adecuado desde el punto de vista de las exigencias de la política urbanística y territorial de la Generalitat Valenciana, tal y como se recoge en el art. 40 LRAU. Así, se propone la clasificación de SNU con un carácter meramente residual respecto al Suelo Urbanizable, con una ocupación masiva del territorio por este último (1.254 Ha) sin que resulte justificada la propuesta planteada, ni desde el modelo territorial que se plantea, ni desde las propias necesidades del municipio, al respecto recordar que en la gestión del anterior PGOU tan sólo se han desarrollado 70,7 Ha de Suelo Urbanizable Programado del total de 255,52 Ha previstas en el mismo (...)». 
la Conselleria de Medio Ambiente, de inicio del proceso de revisión y ordenación de su PRUG, que conlleva la prohibición de realizar actos que supongan una transformación de las condiciones físicas de la zona y el otorgamiento de licencias de obras en suelo urbanizable; en abril de 2001 ya se había procedido a iniciar las obras de urbanización con la eliminación de la vegetación y cultivos existentes ${ }^{9}$. Pero además de mantener la finca $E l$ Raso como suelo urbanizable, el citado proyecto presentado a concierto previo contemplaba, entre otras actuaciones, la incorporación de 447 Ha como suelo urbanizable sin sectorizar asimismo colindantes con el parque natural, en una zona de cultivo tradicional, que provocó el rechazo de los particulares afectados, en su mayoría contrarios a la urbanización de sus parcelas. En el primer caso como en este último, el Estudio de Impacto Ambiental que acompaña a la propuesta de plan general establece, como medidas correctoras del previsible impacto ecológico-paisajístico sobre la laguna de La Mata, la conveniencia de dejar libre de edificación una anchura variable entre 270 y 340 m desde el límite del parque natural que será de cesión obligatoria, quedando dividida a su vez en dos zonas, una libre de urbanización comprensiva de los primeros 100 metros del perímetro de protección que no computará a efectos urbanísticos, y otra sobre la superficie restante que se tendrá en cuenta en el cálculo de zonas verdes. Por el contrario, en la zona delimitada entre esta última y el límite de los $500 \mathrm{~m}$ del perímetro de protección, se permite la vivienda unifamiliar aislada ${ }^{10}$.

En cierto modo, apoyadas en la oferta turística del litoral y aprovechando el reciente tirón de la construcción, los municipios interiores también prosiguen su peculiar especialización turística-residencial con la delimitación de nuevos sectores de suelo, para la construcción de urbanizaciones particulares. En estos municipios, la externalidad que supone la proximidad de las lagunas como elementos de valor ecológico-paisajístico que eleva la calidad ambiental del marco físico y contribuye a cualificar las promociones, se convierte en un factor de localización de los nuevos proyectos urbanísticos que de ningún modo revierte positivamente en el parque natural. Así, por ejemplo, el PGOU de 1999 de Rojales, municipio que linda por el este con el municipio de Guardamar del Segura y por el sur con la laguna de La Mata, y que destaca por poseer el núcleo residencial de Ciudad Quesada —una macrourbanización (2.857.900 $\mathrm{m}^{2}$ y 4.319 viviendas previstas) iniciada a mediados de los años setenta y cuyo plan parcial se aprobó en 1982_, incluye la delimitación de tres sectores de suelo urbanizable (SN/6, S/N7 y S/N8) en las proximidades de la citada laguna. El desarrollo de tales sectores supondría la ocupación y urbanización de 136 Ha y, en principio, la construcción de 4.182 viviendas, según una densidad máxima prevista de 31 viv./Ha. A pesar de contemplar la creación de un Parque Botánico de $407.084 \mathrm{~m}^{2}$, correspondientes a la franja de $500 \mathrm{~m}$ del perímetro de protección que afecta a estos sectores, estas actuaciones lógicamente incrementarían la presión poblacional, alrededor de 12.500 personas, sobre la laguna y su fauna, además de alterar su funcionamiento, ya que se disponen en el flanco septentrional de su cuenca vertiente como continuación de Ciudad Quesada, llegando hasta el propio perímetro de protección y junto a una zona de protección especial integral según el PRUG, en atención a la nidificación de distintas especies y el buen estado de conservación de la vegetación.

9 Según las últimas noticias relativas a la situación de esta zona y su futura urbanización, parece que se ha llegado a un acuerdo entre la promotora Villamartin, el Ayuntamiento de Guardamar y la Conselleria de Medio Ambiente, sobre el retranqueo de la urbanización respecto del límite del parque, tal como plantea el Estudio de Impacto Ambiental que acompaña a la propuesta de Revisión del PGOU de Guardamar del Segura, en trámite de aprobación. Información, 26 de octubre de 2001.

10 Expte. PL 980494/76. STU. COPUT. 
Por su parte, las Normas Subsidiarias (NNSS) de planeamiento del municipio de Los Montesinos, aprobadas en 1995, proponen una compaginación de usos aprovechando la cercanía del Parque Natural sin perjudicar sus valores ambientales y, en este sentido, establecen como usos adecuados en el perímetro de protección el desarrollo de actividades recreativas con carácter naturalístico (observatorios, aulas de la naturaleza, etc.). La ordenación de usos de esta forma planteada en la zona de influencia del parque dispone una primera franja de $150 \mathrm{~m}$, clasificada como SNU de Protección de los Valores Naturales y Ecológicos, destinada al mantenimiento de la actividad agropecuaria existente y a la conservación de la vegetación natural, aunque también establece la creación de un parque de palmeras y la ampliación de la depuradora de aguas localizada en dicha zona, infraestructura que en repetidas ocasiones ha protagonizado situaciones conflictivas por el vertido de aguas residuales dentro del parque natural, con el consiguiente daño ambiental. Las edificaciones permitidas en estos terrenos se restringen a las instalaciones propias de la explotación agrícola y a las relacionadas con el disfrute del medio natural, que se concretan en una aula de la naturaleza y un albergue juvenil. A continuación de esta última, la superficie restante hasta el límite de los 500 m, se clasifica como SNU Agrícola, asociada a un uso mixto, con predominio de las labores agropecuarias y la previsión de un uso lúdico apoyado en obras de escasa entidad, como campings y áreas deportivas recreativas.

No obstante, como hemos tenido ocasión de observar en los municipios vecinos, la presencia del ENP también se aprovecha para ubicar, en su proximidad, los sectores de suelo urbanizable para el desarrollo de segundas residencias. De este modo, con la correspondiente anuencia del principal órgano del poder municipal, el papel de elemento condicionante que debería tener el Parque Natural, se reduce a un mero factor de atracción y se convierte en una externalidad positiva para las promociones inmobiliarias privadas. El modelo territorial que, en consecuencia, se propone carece de toda lógica urbanística ya que los nuevos sectores se sitúan junto a la laguna de Torrevieja, en el extremo SE del término municipal, alejándose del casco urbano e, incluso, ocupan una zona con riesgo leve de inundación, circunstancia puesta de relieve en la Declaración de Impacto Ambiental preceptiva a la tramitación y aprobación del citado documento de planeamiento, además de tener efectos negativos en el paisaje, así como en la modificación del drenaje y, por tanto, de todo el ecosistema. Pero el emplazamiento no es el único rasgo cuestionable porque, además, el aumento de la población previsto es desmesurado (censo actual de 2.200 habitantes y un techo de población de 7.462), basada en las expectativas de la actividad residencial, de acuerdo con el modelo de crecimiento de los municipios anteriormente citados. Incluso, lejos de cualquier lógica ya que, como se contiene en la memoria, se clasifica y califica el suelo atendiendo más a una «posible» situación del mercado e incidencia de la legislación sobre el SNU, que a una certeza concreta y exacta de que la totalidad de este suelo sea desarrollado en el periodo de vigencia de las NNSS, lo que traduce los deseos de sumarse a las dinámicas territoriales ligadas al desarrollo de la actividad turística-residencial.

\section{Otras afecciones territoriales sobre el espacio natural de las Lagunas de Torrevie- ja y La Mata}

Las lagunas de Torrevieja-La Mata, junto con otras tres zonas húmedas — dos de ellas, las Salinas de Santa Pola y El Hondo, con las que guardan una estrecha relación, localizadas también en el sur de Alicante, y una tercera en Castellón-, se sumaron a los espacios naturales protegidos valencianos a finales de 1988, al ser declaradas por la administración autonómica parajes naturales, figura de protección creada por la Ley 5/1988, de 24 de 
junio, de Parajes Naturales de la Comunidad Valenciana. En el caso de las lagunas, la omisión del dictamen del Consejo de Estado en la tramitación del expediente incoado para su aprobación, motivó la anulación de su decreto de constitución y su sustitución por el Decreto 237/1996, de 10 de diciembre de Parque Natural, según categoría contemplada en la Ley 11/1994, de Espacios Naturales Protegidos de la Comunidad Valenciana (LENP), que deroga la anterior y desarrolla la ley básica estatal 4/1989, de 27 de marzo, de Conservación de los Espacios Naturales y de la Flora y Fauna Silvestres.

Las lagunas de Torrevieja-La Mata, al igual que los otros enclaves citados, además de gozar de una protección especial derivada de su declaración como ENP, al amparo de la legislación referida, se incluyen en el Catálogo de Zonas Húmedas previsto por la citada ley autonómica, que establece un régimen de protección general para las mismas, al que se suma el que depara su naturaleza de bienes de dominio público hidráulico y marítimoterrestre. Esta condición demanial establecida por la legislación básica en materia de aguas y de costas, exige su clasificación como SNU sujeto a especial protección, tal como dispone la Ley 4/1992, de 5 de junio, sobre Suelo No Urbanizable. Por último, estos distintivos derivados de las normativas autonómica y estatal, se completan con el reconocimiento, a escala internacional, que supone su designación como Zonas Húmedas de Importancia Internacional (Convenio de Ramsar) y como Zonas de Especial Protección para las Aves (ZEPAs), en relación con la D79/409/CE, de Aves Silvestres, y, por supuesto, su inclusión en la Red Natura 2000, prevista en la D92/43/CE de Hábitats naturales y de la fauna y flora silvestres, al ser propuestas como Lugar de Interés Comunitario (LICs) por el ejecutivo valenciano.

\section{Ordenación y gestión del parque natural}

La ley 11/1994, que tiene por objeto establecer el régimen aplicable a los ENP, señala entre los criterios a aplicar, la conservación de los recursos naturales desde el punto de vista de su uso sostenible con criterios de ecodesarrollo. Con estas premisas, su artículo séptimo define los parques naturales como áreas naturales que, en razón a la representatividad de sus ecosistemas o a la singularidad de su flora, su fauna, o de sus formaciones geomorfológicas, o bien a la belleza de sus paisajes, poseen unos valores ecológicos, científicos, educativos, culturales o estéticos, cuya conservación merece una atención preferente y se consideran adecuados para su integración en redes nacionales o internacionales de espacios protegidos. De acuerdo con su importancia, dicha ley dispone que las actividades a realizar en ellos se orientarán hacia los usos tradicionales agrícolas, ganaderos y silvícolas, y a la explotación de las producciones compatibles con las finalidades que motivaron la declaración, así como a su visita y disfrute con las limitaciones necesarias para garantizar su protección. Las lagunas, en razón a la representatividad de sus ecosistemas y a las actividades económicas que acogen, encajan perfectamente en esta categoría que afecta a los espacios de máximo valor pero, también, al mismo tiempo, de mayor implantación de usos, en los que se favorece el aprovechamiento público conforme a su, en principio, elevada potencialidad recreativa. Mientras, en otras figuras, salvo en la de paisajes protegidos, señala expresamente que se podrá limitar la utilización de los recursos naturales y los usos tradicionales, así como las visitas y actividades de recreo.

En ausencia de Plan de Ordenación de Recursos Naturales (PORN), instrumento de gestión introducido por la Ley 4/1989, de 27 de marzo, de Conservación de los Espacios Naturales y de la Flora y la Fauna Silvestres, el régimen de protección y la ordenación de usos correspondiente quedan establecidos en su Plan Rector de Uso y Gestión (PRUG), aprobado siete años después de su creación. No obstante, hay que tener en cuenta el 
alcance más restringido de este último, ya que su ámbito de aplicación se reduce exclusivamente al espacio natural protegido y a su área de amortiguación de impactos que, en este caso, como en otros, se establece sobre una franja de $500 \mathrm{~m}$ de anchura, en torno a los límites del parque. La estricta regularidad de la anchura de esta zona, prueba más que suficiente de la falta de atención a los criterios geográficos, fisiográficos, ecológicos o funcionales a los que remite la LENP para su delimitación (art. 29.4), así como su estrechez ante la consolidación de la urbanización turístico-residencial en su entorno inmediato, cuestionan claramente su pretendida eficacia en la amortiguación de impactos, máxime cuando en la práctica no existe en la regulación de usos y actividades correspondiente, ninguna restricción prevista para la misma en dicho documento, excepto la prohibición de vertederos y el uso de determinados productos fitosanitarios relacionados con el cultivo agrícola. Además, en el conjunto de medidas contempladas para procurar la protección, por lo que respecta a las áreas de amortiguación de impactos, únicamente dispone, en virtud del epígrafe noveno del Anexo I del Reglamento para la ejecución de la Ley 2/1989, de Impacto Ambiental, la exigencia del trámite de evaluación ambiental para una serie de obras, instalaciones y actividades, entre las que no se mencionan los planes parciales de carácter residencial que, al igual que las construcciones de utilidad pública o interés social, se sujetan sólo a Estimación de Impacto ambiental.

Precisamente el PRUG de este paraje, junto con los del Hondo y las Salinas de Santa Pola, asimismo afectados por un perímetro de protección de la misma amplitud, se encuentran en proceso de revisión por Orden de 1 de junio de 2000 de la Conselleria de Medio Ambiente, con el propósito de examinar y dar una nueva ordenación a la zona periférica establecida en $500 \mathrm{~m}$ alrededor de cada parque, y mejorar así la preservación de los valores ecológicos, naturales y paisajísticos. Según la citada orden, la revisión deberá crear un modelo territorial sostenible basado en una ordenación que, con una visión a largo plazo, compatibilice los usos antrópicos y la protección de los valores naturales. Además, esta iniciativa propone aplicar un tratamiento conjunto e integral de los tres ámbitos protegidos afectados, en atención a su proximidad, las estrechas relaciones que guardan entre sí y la similitud de afecciones que presentan, fundamentalmente de carácter urbanístico.

De todos modos, la importancia del PRUG es evidente ya que, según el artículo 37 de la citada LENP, constituye el marco en que han de desenvolverse las actividades directamente ligadas a la declaración del espacio natural protegido y, en particular, la investigación, el uso público y la conservación, protección y mejora de los valores ambientales. Así pues y por lo que respecta al PRUG de las Lagunas de Torrevieja y La Mata, en cuanto instrumento normativo para la regulación y ordenación del uso público, contempla en su Programa de Actuación, un Plan de Uso Público dirigido a regular y programar la realización de actividades y actuaciones necesarias para cumplir los objetivos de información, observación, interpretación y educación. En concreto, las actuaciones propuestas a llevar a cabo con tal finalidad se concretan en el establecimiento de itinerarios, adecuación-dotación de áreas para uso naturalístico extensivo, creación de un centro de recepción e interpretación, programa de visitas y campaña informativa y divulgativa.

De esta forma, la normativa del PRUG distingue a efectos de uso público dos tipos de espacios y, más concretamente, entre espacios de acceso libre y espacios de acceso controlado. Los primeros son zonas que presentan estacionalmente un elevado índice de ocupación y utilización pública tradicional, cuya localización se corresponde con las áreas sometidas al grado de protección especial ecológica por su alto valor ambiental, constituidas por el perímetro de protección previsto para la laguna de La Mata, la zona forestal de la redonda de dicha laguna, los espacios abiertos de matorral y parcelas de cultivo existentes en la misma y, además, la orilla oriental de la laguna de Torrevieja por la proximidad de 
las urbanizaciones y presentar un uso público relativamente intenso. Estas zonas forman un sistema complementario a las áreas de protección especial integral y desempeñan una función primordial en su protección. El Plan prevé su utilización pasiva como áreas de ocio y esparcimiento en relación con el disfrute del medio natural (senderismo controlado o recreo pasivo), pudiendo contar sólo con equipamientos e infraestructuras de carácter blando, destinadas a facilitar el uso recreativo-naturalístico del paraje, tales como señalización de itinerarios y senderos, realización de miradores y observatorios.

Como espacios de acceso controlado se consideran aquéllos que, por su mayor valor ecológico, están sujetos al grado de protección especial integral y no permiten un uso público masivo o incontrolado, englobando la laguna de La Mata y las playas, así como el carrizal y el saladar que circunda ambas lagunas, salvo la orilla oriental de la laguna de Torrevieja. En ellos sólo se admiten equipamientos e infraestructuras de carácter blando, destinadas a facilitar el conocimiento directo de los valores del parque y la realización de actividades didáctico-ecológicas (itinerarios y observatorios). Para la realización de estas actividades se prevé el establecimiento de un programa de visitas guiadas con calendario y limitación del número máximo visitantes.

\section{El Plan de Ordenación de Uso Público del Parque Natural de las Lagunas de Torrevieja y La Mata y propuestas de la corporación municipal}

Si bien la gestión y conservación del parque corresponde a la Conselleria de Medio Ambiente, la mayor implicación del Ayuntamiento de Torrevieja en estas tareas y, en particular, en la elaboración del Plan de Ordenación del Uso Público (POUP) del Parque Natural de las lagunas de Torrevieja y La Mata, tiene como respaldo un Convenio Marco suscrito en 1996 con la Conselleria de Agricultura y Medio Ambiente para la realización de actuaciones en el parque natural. Sobre esta particularidad, la memoria de actividades del parque natural, correspondiente al periodo 1996-1999, recoge que es en el transcurso del año 1996 cuando se inician las relaciones entre el consistorio y la dirección del parque, las cuales parecían no existir con anterioridad a dicha fecha, tal como señala el guía-guarda en uno de sus informes. No obstante, hay que señalar que es en estos momentos cuando se emprende una política de conservación más activa tras la aprobación del PRUG, llevándose a cabo la creación del centro de información, la instalación de vallados y el cierre de caminos para frenar las agresiones al medio, y comenzar al año siguiente con la señalización del parque, la construcción de tres observatorios ornitológicos y la construcción de una isla artificial para nidificación de las aves.

En cuanto al mencionado convenio, el consistorio se comprometía a redactar el POUP y a ceder unos terrenos de propiedad municipal, con una superficie total en torno a $100 \mathrm{Ha}$, repartidos entre el perímetro de protección y el interior del propio parque, con el propósito de aliviar la presión sobre las áreas de mayor valor ecológico y dar cabida a las distintas actuaciones relacionadas con su uso público.

De esta forma, el proyecto de POUP fue redactado por el Instituto de Ciencias Sociales y Ambientales (ICSA) en el año 1997, a instancia del Ayuntamiento de Torrevieja, interesado en regular actividades recreativas (baños de lodo, pic-nic, paseos) que habitualmente se realizan de forma improvisada y sin control, con el propósito de garantizar una utilización óptima de los recursos disponibles ${ }^{11}$.

11 Si bien el proyecto de POUP fue presentado a la Junta Rectora del Parque Natural en julio del año 2000 para su valoración, las objeciones planteadas por el Servicio de Costas del Ministerio de Medio Ambiente, relativas a la servidumbre de protección de $500 \mathrm{~m}$, exigen su modificación, de manera que el plan estudiado no es el definitivo. No obstante, aún a pesar de estas circunstancias, el análisis de este documento se ha considerado de 
Entre los motivos que reclaman una adecuada ordenación del uso público, en la memoria del POUP, se destaca el progresivo aumento de visitantes, cuyo número, se estima, llegaría a 343.000 en el año 2005, cifra que duplicaría el registro actual. Este incremento se relaciona con la necesidad de zonas verdes de los residentes, la práctica del baño con fines terapéuticos y el creciente reconocimiento de sus valores naturales entre el público en general. Así, por ejemplo, se señala la tendencia al alza de su uso educativo aunque insuficientemente atendido por la falta de medios, infraestructuras y recursos humanos ${ }^{12}$. Precisamente este último contribuye en la actualidad a explicar una cierta desestacionalización de la demanda, hasta el momento principalmente veraniega, favorecida por una demanda educativa que sobrepasaría los recursos existentes, a la que se suma la turística también en alza estos últimos años. En particular, se destaca la importancia de la afluencia motivada por los baños de lodo y salinos que explicaría el 41,56 \% de las visitas que recibe el parque y motivaría la elección de Torrevieja como destino para el $30 \%$ de los turistas acogidos en el municipio. Respecto a este uso, se señala además su máxima concentración en el borde oriental de la laguna de Torrevieja, más concretamente en el sector de la Punta de la Víbora y en otras zonas colindantes con urbanizaciones. Incluso, calcula que este tipo de aprovechamiento representa el $8 \%$ de la contribución de la industria turística, sobre todo en concepto de alquiler de apartamentos.

Otro factor que asimismo justifica la necesidad del POUP es la propuesta de un proyecto de protección de la laguna de Torrevieja elaborado por la Nueva Compañía Arrendataria de las Salinas, consistente en la construcción de un canal en su extremo meridional que evitaría la entrada de agua dulce, con el fin de potenciar la zona para la nidificación de aves y mejorar el proceso de producción de sal. Sin embargo, su aplicación, a criterio de los redactores, redundaría en una merma del uso público al limitar el acceso a sus orillas, de manera que se vería comprometida la creciente demanda y sus expectativas de desarrollo futuro, generando una situación conflictiva.

En cuanto al grado de conocimiento del parque natural por parte de los usuarios y su compromiso con la conservación del medio ambiente, la Memoria señala que el 26,2 \% de las personas encuestadas ignoran que se encuentran en un espacio natural protegido de propiedad estatal, cuya gestión escapa al Ayuntamiento. Más importante resulta, sin embargo, el dato de que ninguna de ellas conoce la existencia del Centro de Interpretación y los itinerarios guiados. Además, del conjunto de personas entrevistadas, el $38 \%$ no son respetuosos con el medio y un 26,2 \% sólo lo son en ocasiones, frente a un 29,5 \% que sí mostrarían una mayor responsabilidad ambiental.

Todas estas cuestiones plantean en definitiva la necesidad de emprender tareas de información, interpretación y educación ambiental en relación con los valores y el conocimiento del parque, dirigidas a sus visitantes. De este modo, el POUP propone entre sus

gran interés, tanto por sí mismo, ya que se trata de un instrumento de planificación hasta el momento no empleado en nuestra Comunidad Autónoma - aunque también se encuentra redactado el correspondiente al Parque Natural de la Font Roja pero, como el que nos ocupa, sin aprobación definitiva por el momento-, como por las propuestas que contiene y que sin menoscabo de las rectificaciones que sufra, se pueden tomar prácticamente como determinantes.

12 En concreto, el equipo humano encargado del parque está compuesto por un director-conservador que, asimismo, lo es de los parques naturales del Hondo y de las Salinas de Santa Pola, un monitor y un guía guarda, cuya misión principal es vigilar, aunque en esta labor también participa la guardería forestal de la comarca de la Vega del Bajo Segura, compuesta por un jefe y cinco agentes, así como con la del SEPRONA. De hecho en las memorias de actividades del parque natural se expone la conveniencia de incrementar la ayuda de este último cuerpo de la Guardia Civil y, también, de la policía local de Torrevieja. El parque cuenta además con una brigada de mantenimiento, compuesta por un capataz y cinco peones, que atienden igualmente a los tres parques naturales. 
objetivos establecer una serie de planes y programas de actuación para canalizar las actividades de uso público, relacionadas con los recursos naturales y culturales del parque natural, fomentando su conocimiento y valoración, al mismo tiempo que un cambio de actitudes y comportamiento hacia ellos y el medio ambiente en general. Con esta finalidad, la metodología empleada, compatible con la correcta conservación de los valores naturales, consiste en la elaboración de un diagnóstico de la situación actual y de las expectativas relacionadas con el uso público, junto con la delimitación de unidades ambientales, a partir de las cuales propone en primer lugar una zonificación en función de su potencialidad de uso público y, en segundo lugar, la asignación de un sistema de aprovechamiento a cada zona, con la correspondiente previsión de infraestructuras y medidas necesarias para la ordenación del uso público (vid. cuadro $n^{\circ} 1$ y mapa $n^{\circ} 3$ ). En este sentido, el POUP, conforme con las indicaciones del Plan de Acción para los Espacios Protegidos del Estado Español, incluye junto a la propuesta de ordenación, un programa de infraestructuras, un plan de medidas correctoras y compensatorias, un programa de comunicación, interpretación y educación ambiental, un programa de publicaciones, un programa de señalización, un plan de vigilancia y seguimiento, un estudio económico-financiero y un plan de viabilidad, completándose con un estudio de impacto ambiental.

\section{Cuadro $\mathrm{n}^{\mathrm{o}} 1$}

INFRAESTRUCTURAS Y EQUIPAMIENTOS PROPUESTOS EN EL POUP

\begin{tabular}{|c|c|c|c|}
\hline $\begin{array}{l}\text { INFORMACIÓN } \\
\text { Y ACOGIDA }\end{array}$ & $\begin{array}{l}\text { EDUCATIVAS Y } \\
\text { CIENTÍFICAS }\end{array}$ & DISUASORIAS & $\begin{array}{l}\text { SOCIO-RECREATIVAS } \\
\text { Y TURÍSTICAS }\end{array}$ \\
\hline $\begin{array}{l}\text { Punto de información } \\
\text { permanente } \\
\text { Punto de información } \\
\text { temporal }\end{array}$ & $\begin{array}{l}\text { Centro de recepción } \\
\text { Centro de interpretación } \\
\text { Área interpretativa al aire } \\
\text { libre } \\
\text { Ecomuseo } \\
\text { Aula de la Naturaleza } \\
\text { Jardín didáctico } \\
\text { Observatorio científico } \\
\text { Observatorios y miradores } \\
\text { de uso público } \\
\text { Pasarelas peatonales elevadas } \\
\text { Itinerarios }\end{array}$ & $\begin{array}{l}\text { Vallados y cercas } \\
\text { Barreras y quitamiedos } \\
\text { Pantallas vegetales } \\
\text { Cierres de caminos } \\
\text { Bandas sonoras }\end{array}$ & $\begin{array}{l}\text { Aparcamientos disuasorios } \\
\text { Áreas recreativas } \\
\text { Áreas de reposo } \\
\text { Áreas de picnic } \\
\text { Barbacoas/cocinas } \\
\text { Balneario } \\
\text { Espacios biosaludables } \\
\text { Equipamientos comerciales: } \\
\text { ecotienda y centro de } \\
\text { servicios (guías, alquiler de } \\
\text { bicicletas, etc.) } \\
\text { Equipamientos deportivos }\end{array}$ \\
\hline
\end{tabular}

Fuente: Proyecto de Plan de Ordenación de Uso Público del Parque Natural de las Lagunas de La Mata y Torrevieja. Elaboración propia.

Un tema de suma importancia es la zonificación planteada que, acorde con las particularidades del parque, la existencia de elementos valiosos y frágiles en su periferia y los criterios defendidos por la Federación de Parques Naturales y Nacionales de Europa, ha consistido en definir zonas de uso público extensivo con distinto grado de protección (itinerarios y observatorios), rodeadas de infraestructuras de recepción e interpretación y ejes de desplazamiento. A éstas se añaden los terrenos municipales que albergan las actividades e infraestructuras de uso público de carácter intensivo, previendo zonas intermedias de restauración ecológica y paisajística. En concreto, de acuerdo con estas pautas, la propuesta de zonificación incluye las nueve categorías siguientes de espacios: áreas de reserva natural dirigida correspondientes a zonas de protección integral en el PRUG, en las 


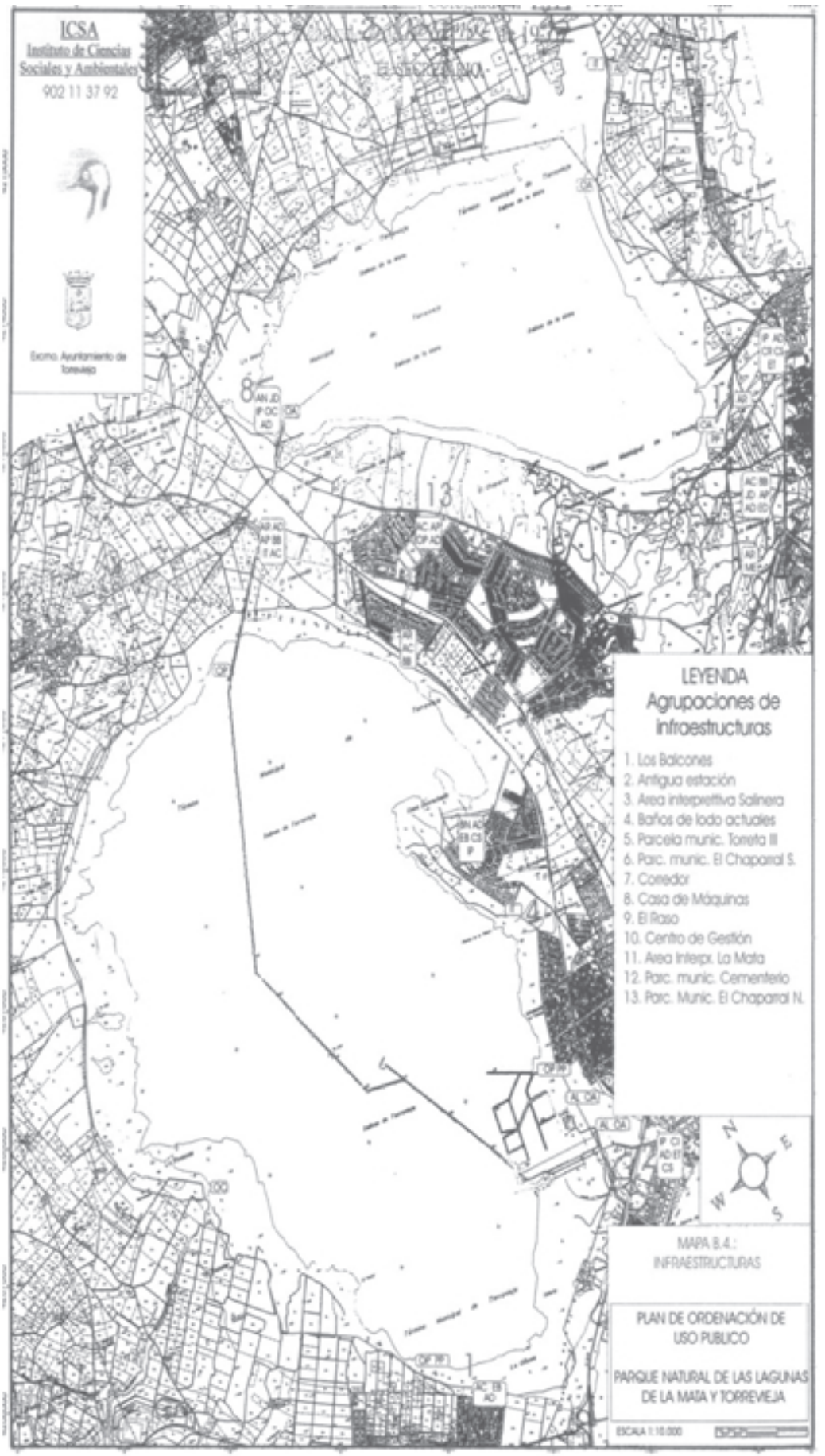

MAPA N ${ }^{0}$ 3: Infraestructuras previstas en el POUP. 


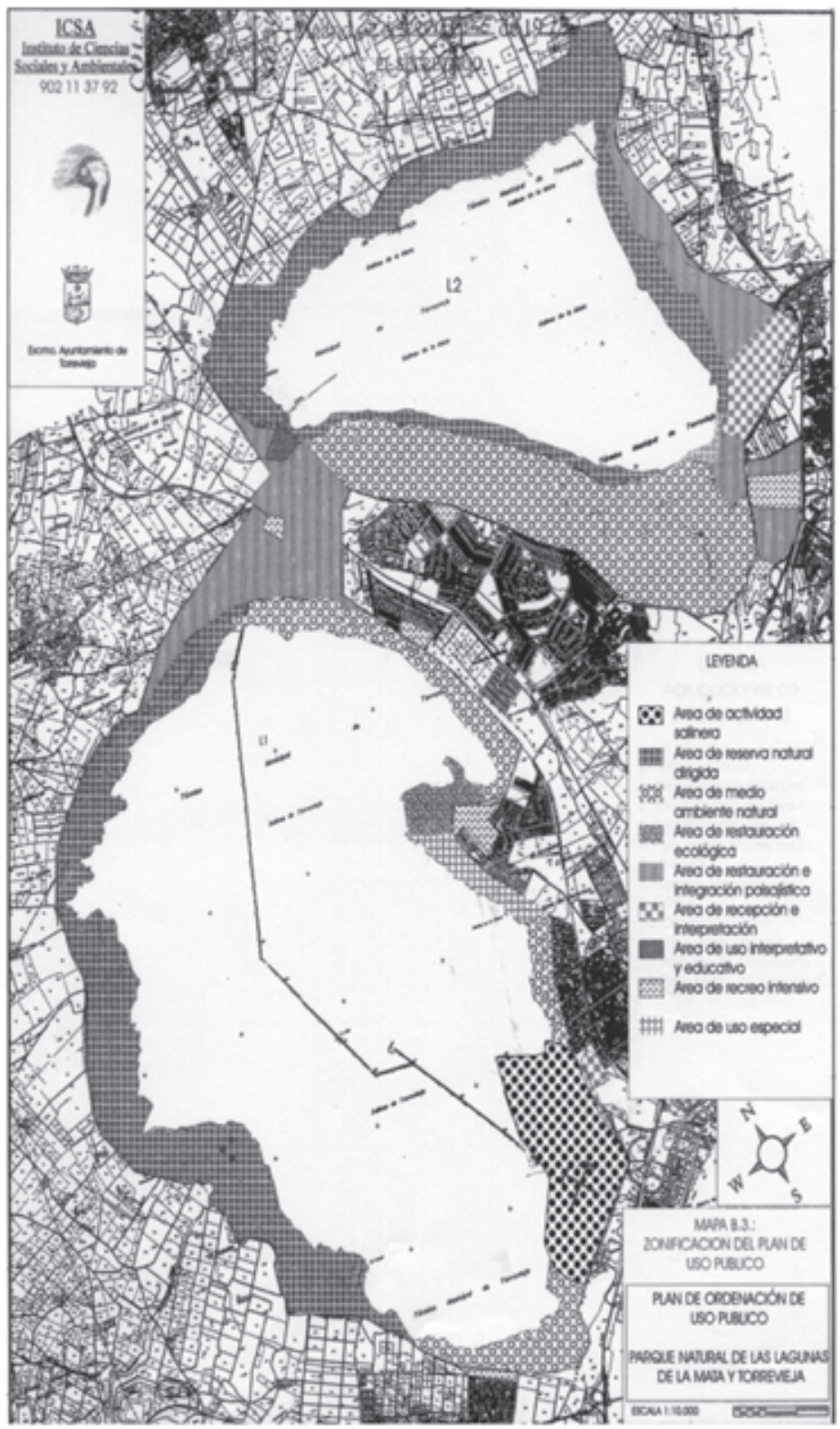

MAPA N $\mathrm{N}^{\mathrm{O}}$ 4: Zonificación propuesta en el POUP.

Fuente: proyecto del POUP del Parque Natural de las Lagunas de Torrevieja y La Mata.

Abreviaturas. AC: área recreativa, AD: aparcamiento disuasorio, AL: área interpretativa al aire libre, AN: aula de la naturaleza, AP: área picnic, AR: área de reposo, BB: cocinas, BN: balneario, CI: centro interpretación, CR: centro de recepción e interpretación, CS: centro de servicios, EB: espacio biosaludable, ED: equipamientos deportivos, ET: Ecotienda, IP: centro de información, IT: punto de información temporal, JD: jardín didáctico, ME: mirador escénico, OA: observatorio ornitológico, OC: observatorio científico, OP: observatorio paisajístico, PP: pasarela peatonal. 
que no se admite el uso público; zonas de medio ambiente natural coincidentes con áreas de protección especial ecológica, en las que sí se permite, pero con presencia mínima de infraestructuras (itinerarios y observatorios); áreas de restauración ecológica que engloban zonas cuya finalidad es la recuperación de sus biotopos, áreas de restauración e integración paisajística constituidas por zonas del interior del parque, perímetro de protección y otras cercanas que actuarían como áreas tampón; áreas de recepción e interpretación en torno a los equipamientos, diseñadas para cumplir tales funciones de acogida y atención al público; áreas de uso interpretativo y educativo destinadas a poner en contacto a los visitantes con los valores del parque fuera de las instalaciones de recepción; áreas de recreo intensi-

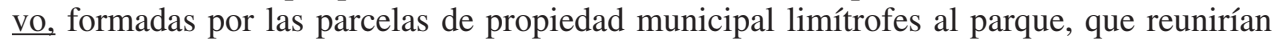
los principales equipamientos e infraestructuras para servir de base de operaciones (aparcamientos, descanso, comida, recreo y deportes no vinculados al parque) a los usuarios que llevan a cabo actividades dentro del parque, sin la correspondiente regulación u ordenación; áreas de uso especial asimismo orientadas al uso público, pero con carácter temporal, ya que se prevé su mejora para pasar a zonas de medio ambiente natural y, por último, áreas de actividad salinera (vid. mapa $\mathrm{n}^{\circ} 4$ ).

A partir de esta zonificación y sin considerar las áreas de reserva natural y las dedicadas a la actividad salinera y al cultivo de la vid, el estudio realizado estima la superficie potencialmente utilizable con fines de uso público en 707,7 Ha y la capacidad de acogida recreativa en 1.348 personas de forma simultánea, resultante de aplicar una capacidad de carga ecológica variable de 5 a 1 personas/Ha según zona, lo que arrojaría una densidad media de 2 personas por Ha. La indicada cifra de 1.348 personas superaría la media del número de visitantes diarios, aunque se apunta que la distribución sería bastante más homogénea en comparación con la situación actual, dado que el $52 \%$ de los efectivos se concentran en la Punta de la Víbora, frente a la urbanización Torreta III, atraídos por la práctica de los baños de lodo. A esta zona se suman, como áreas más frecuentadas, la pinada de la redonda de la Mata y las orillas de la laguna de Torrevieja en sus extremos sudoeste y nordeste, frente al conjunto residencial Los Balcones y junto a la urbanización El limonar-El Chaparral, respectivamente.

Sin embargo, no se concreta la tasa de renovación de visitantes correspondiente a cada zona del parque, según tipo de uso asignado, y sólo se establece un máximo de 4 para las áreas más frecuentadas, lo que impide estimar la capacidad máxima diaria de uso público $\mathrm{y}$, en definitiva, la capacidad de carga para el conjunto del parque.

La máxima intensidad de uso público ( 5 personas/Ha) en el conjunto de zonas diferenciadas en el interior del parque, se asigna a unos sectores que en la actualidad ya soportan una importante frecuentación, como son las orillas de la laguna de Torrevieja aledañas a las urbanizaciones Torreta III, El Chaparral y los Balcones, junto con el espacio intermedio de comunicación sin urbanizar entre las dos lagunas. En la propuesta de zonificación del POUP, la primera de estas zonas se delimita como área de uso especial y las dos siguientes como áreas de medio ambiente natural, mientras la última se incluye en la de restauración e integración paisajística. Si a la vez, relacionamos esta propuesta con la clasificación de espacios establecida en el PRUG, según régimen de protección, se observa entonces que a las dos primeras les corresponde el grado de protección especial ecológica, a la tercera el de protección integral y, a la última, el de protección paisajística (vid. mapa no 5). Además, junto a estas zonas se localizan las cuatro parcelas, propiedad del Ayuntamiento, incluidas en el perímetro de protección y contiguas al límite del parque, lindando todas ellas con las zonas de protección especial ecológica, excepto la de Los Balcones que lo hace con un sector de protección integral, es decir, el máximo grado de protección, a pesar de lo cual se le asigna un uso recreativo intensivo. 


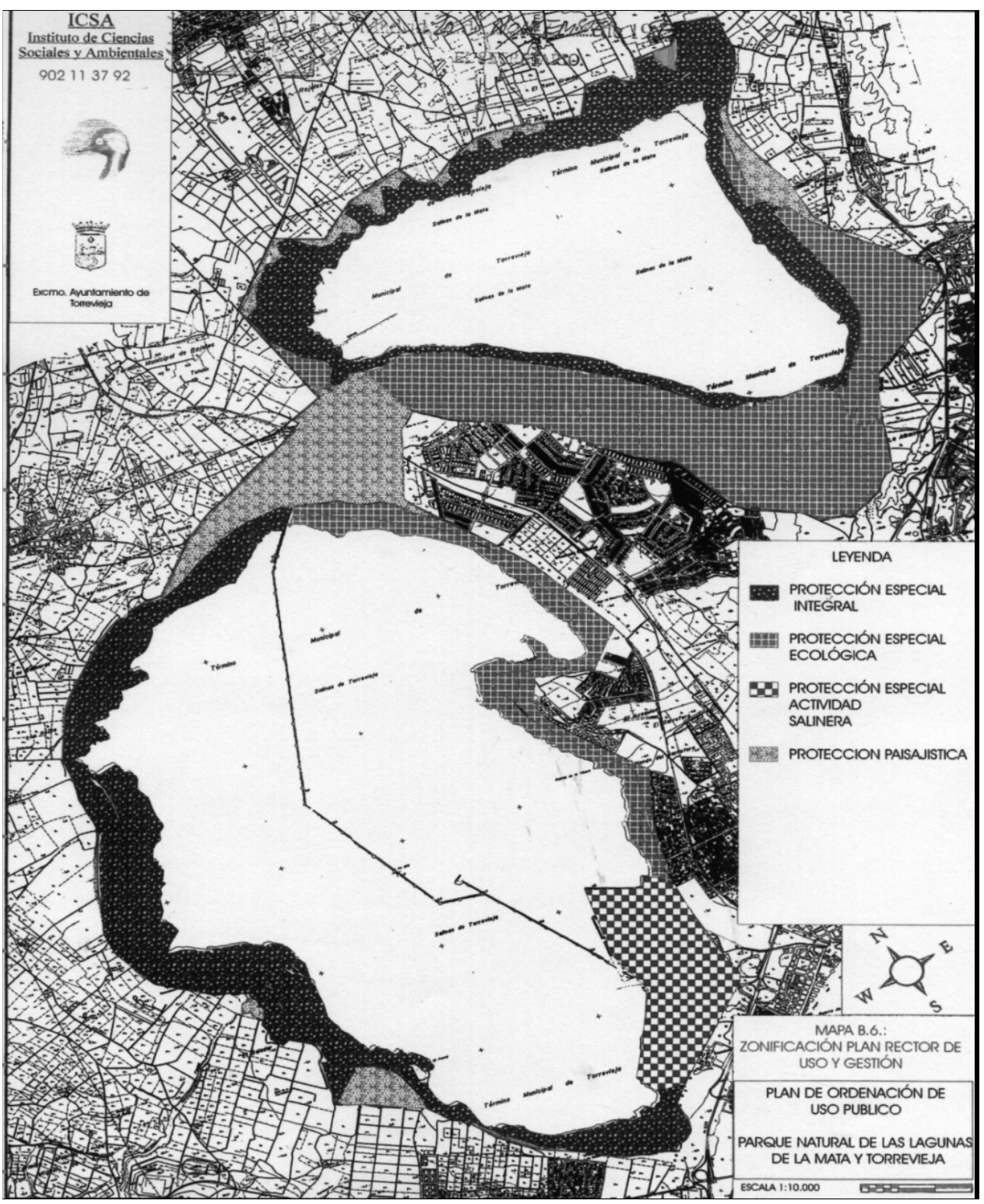

MAPA N ${ }^{\circ}$ 5: Zonificación del Plan Rector de Uso y Gestión del Parque Natural de las Lagunas de Torrevieja y La Mata. Fuente: Conselleria de Medio Ambiente.

Ante esta situación, hay que recordar que el PRUG determina para las zonas de protección integral un acceso controlado y actividades didáctico ecológicas, mientras que los espacios sujetos al grado de protección especial ecológica —orilla oriental de la laguna de Torrevieja y parte de la redonda de La Mata - forman un sistema complementario a las áreas de protección especial integral y desempeñan una función primordial en su protec- 
ción. En consecuencia, el artículo treinta y ocho del PRUG dispone como usos permitidos en ellas, todos aquellos dirigidos a conseguir una mejor y más efectiva conservación y potenciación de los recursos naturales, de manera que estarán preferentemente orientadas hacia actividades científicas, de conservación e interpretación de la naturaleza. Considera, no obstante, como usos compatibles aquellos de carácter recreativo o naturalístico que no supongan eventuales riesgos de degradación medioambiental y que impliquen una utilización pasiva del espacio, tales como senderismo controlado o recreo pasivo.

Respecto a estas indicaciones, es cierto que las infraestructuras y equipamientos previstos en el POUP para estas zonas se disponen en su mayor parte, al menos las de carácter recreativo-turístico, fuera de los límites del parque, aunque colindantes y dentro del perímetro de protección fijado por el PRUG ya que, tal como se reconoce, el uso que soportan tiene más un carácter terapéutico o lúdico-recreativo que de disfrute del medio natural, estableciéndose únicamente en la zona intermedia entre ambas lagunas un área de picnic y de barbacoas. Aún así, a pesar de la localización de las restantes actuaciones de este tipo fuera del parque, al igual que la del futuro balneario y centro de servicios a construir junto a la urbanización Torreta III, en la Punta de la Víbora, precisamente con la intención de desplazar ciertos usos incompatibles a la periferia del parque, su cercanía difícilmente evitará su impacto y supondrá una presión añadida sobre el mismo.

Sobre esta última cuestión, el documento incluye un estudio del impacto generado por las actividades inventariadas que tienen como soporte el parque sobre los distintos recursos naturales, considerados individualmente y, además, sin medir la intensidad y signo del impacto, reconociéndose la imposibilidad de establecer la respuesta de los recursos ante distintas intensidades de uso (vid. cuadro $\mathrm{n}^{\circ} 2$ ). Pero, lo que sobre todo se echa en falta es el estudio del impacto ambiental que provocarán las infraestructuras y equipamientos proyectados, así como del uso asociado a los mismos, a lo que se añade la falta de concreción respecto a algunos de los equipamientos previstos - caso de las instalaciones deportivas donde se incluye una pista de aeromodelismo, junto con un indeterminado «otros»—, así como la de sus características concernientes a superficie ocupada o, también, por ejemplo, a la anchura de los itinerarios proyectados.

Cuadro $\mathrm{n}^{\mathrm{o}} 2$

APTITUD DEL PARQUE PARA LA REALIZACIÓN DE ACTIVIDADES

\begin{tabular}{|c|c|c|}
\hline Compatibles & Potencialmente conflictivas & Incompatibles \\
\hline $\begin{array}{l}\text { Andar y correr por los senderos } \\
\text { establecidos. } \\
\text { Circular en bicicleta por viales } \\
\text { Pasear a caballo por viales } \\
\text { Itinerarios autoguiados } \\
\text { Itinerarios guiados } \\
\text { Pintura }\end{array}$ & $\begin{array}{l}\text { Baños de lodo } \\
\text { Baños de agua salada } \\
\text { Tomar el sol } \\
\text { Circular en motocicleta por viales } \\
\text { Circular en automóvil por viales } \\
\text { Picnic/comida fría Barbacoas } \\
\text { Colombicultura } \\
\text { Aeromodelismo } \\
\text { Deportes (golf, fútbol, tenis) }\end{array}$ & $\begin{array}{l}\text { Pasear a pie o a caballo por fuera de los } \\
\text { caminos establecidos. } \\
\text { Circulación rodada por fuera de los viales } \\
\text { establecidos. } \\
\text { Aparcamiento descontrolado } \\
\text { Pasear animales sueltos } \\
\text { Fotografía y observación ajena a los lugares } \\
\text { específicamente habilitados para ello } \\
\text { Recolección de especies } \\
\text { Caza } \\
\text { Ultraligeros } \\
\text { Vertidos no industriales }\end{array}$ \\
\hline
\end{tabular}

Fuente: Proyecto de Plan de Ordenación de Uso Público del Parque Natural de las Lagunas de La Mata y Torrevieja. Elaboración propia. 
Para terminar, hay que destacar el firme interés del Ayuntamiento en la construcción de un balneario y en la potenciación del turismo de salud, como un nuevo elemento que añadir a la oferta tradicional monopolizada por el binomio sol y playa, actuación que además se incluye dentro del conjunto de propuestas incluidas en un Plan de Excelencia concedido al municipio, en el año 2000. De hecho, este proyecto, junto con el redactado para las antiguas Eras de la Sal, asimismo relacionado con la actividad salinera y que representa una importante apuesta por la recuperación del patrimonio cultural, constituyen las actuaciones más emblemáticas previstas en el desarrollo del citado plan, en el marco del programa específico para destinos turísticos del Plan Integral de Calidad del Turismo Español (PICTE 2000) de la Secretaria de Estado de Comercio, Turismo y Pyme. En concreto, dicho programa de Calidad de los Destinos Turísticos incide en el protagonismo de la administración local y en el desarrollo sostenible y, en particular, los Planes de Excelencia tienen como finalidad la recuperación y regeneración de destinos maduros o consolidados a través de la diversificación y enriquecimiento de la oferta, con la puesta en marcha de distintos proyectos con carácter demostrativo, entre los que figuran los destinados a su ordenación y a actuaciones en el medio ambiente natural.

\section{Consideraciones finales. Pros y contras de la propuesta de ordenación del uso público del Parque Natural de las Lagunas de Torrevieja y La Mata}

Como ha quedado expuesto, el caso de estudio pone de manifiesto la incidencia de las decisiones tomadas por el poder municipal, respecto a un espacio de alto valor ecológico declarado parque natural. Particularmente determinantes han sido las relativas a la ocupación y destino del suelo, a través de la aprobación de los documentos de planeamiento urbanístico por parte de los distintos ayuntamientos afectados, a lo que se añade su falta de intervención en la gestión y protección del mismo, principalmente del de Torrevieja, dado que el ENP ocupa una gran parte de su término municipal. Este proceso, que se puede hacer extensivo a otros espacios naturales protegidos, es el origen de efectos negativos que desde hace tiempo complican la gestión y la ordenación de su uso público, sobre todo en aquellos ámbitos en los que también concurre un fuerte desarrollo del turismo de masas. En estos últimos, se da además la circunstancia de que tales espacios adquieren, en la actualidad, un renovado interés como recurso para mejorar y diversificar la oferta turística, a propósito de las estrategias de reestructuración de los destinos turísticos maduros. En consecuencia, ante esta situación, se impone con urgencia coordinar las distintas políticas que inciden en el territorio, en concreto las de urbanismo y conservación de la naturaleza y, por supuesto, muy particularmente, esta última con la turística, para lo cual podrían desarrollarse algunos de los instrumentos de planificación previstos en la Ley de Ordenación del Territorio de la Comunidad Valencia. Entre otras cuestiones, tales planes deberían asegurar la correspondiente adaptación del planeamiento urbanístico de los municipios afectados a la existencia del parque, de manera que se supeditara la clasificación y ordenación del suelo en todo su perímetro, a su mejor protección. Este es precisamente uno de los objetivos que se plantean para el Plan de Desarrollo Urbanístico, según el Documento III de su Avance, publicado en 1995, respecto al Sistema Valenciano de Espacios de Interés Natural propuesto en el mismo.

Ahora bien, si ésta ha sido la pauta habitual, por lo que respecta a la propuesta aquí presentada, dirigida a potenciar, a la vez que ordenar, el uso público del parque natural de las Lagunas de Torrevieja y La Mata, hay que valorar muy positivamente la actual implicación y participación activa del Ayuntamiento de Torrevieja, especialmente, su iniciativa de trasladar algunas de las actividades más molestas a la periferia del parque. Esta actua- 
ción resulta incluso favorecida por el ofrecimiento de varias parcelas del Patrimonio Municipal de Suelo realizado por dicho Ayuntamiento, con la intención de destinarlas a diversas actividades recreativas ligadas al uso público del parque.

De igual manera, hay que destacar la mayor responsabilidad municipal en la ordenación del parque, ya que gran parte de las actuaciones previstas relativas a la ejecución y gestión de las mismas recae en el propio Ayuntamiento, con la consiguiente consignación presupuestaria. Dentro de estas actuaciones relacionadas con la mejora del uso público del parque, sobresale la rehabilitación de la antigua estación de ferrocarril de Torrevieja para acondicionarla como centro de interpretación, otorgando de este modo un nuevo uso a unas instalaciones, en la actualidad, abandonadas. Por su localización, este proyecto tiene además grandes posibilidades de conexión con otros espacios relacionados con el uso público del parque, en concreto, dada su proximidad, con el también futuro centro de interpretación de las salinas al aire libre, y la propuesta de integrarlo con el «acequión» de la propia laguna de Torrevieja, dentro ya del centro urbano, todo ello potenciado por el inicio de una vía verde cicloturística, cuyo trazado sigue el de unas antiguas vías férreas levantadas en 1997, operación que fue asimismo impulsada desde el Ayuntamiento. De hecho, la corporación municipal ha promovido en los últimos años una serie de proyectos, entre los que se incluyen los anteriores y, también, el ya citado de las Eras de la Sal, que suponen una importante apuesta por recuperar y conservar el patrimonio natural y cultural de la comunidad.

No obstante, dentro de estas actuaciones, también se prevé la ocupación de algunas de las parcelas citadas, con el fin de adecuarlas a un uso recreativo más intensivo e, incluso, una de ellas se destina a la construcción de una estación balnearia, cuyas características edificatorias no se especifican en el POUP, aunque su proyecto y diseño arquitectónico ya han sido presentados al público ${ }^{13}$. Una iniciativa similar, junto con un espacio biosaludable, se ha puesto en práctica con éxito en las salinas de San Pedro del Pinatar, municipio de la provincia de Murcia, próximo al área de estudio. Sin embargo, el proyectado junto a la laguna de Torrevieja, precisamente por su proximidad al parque, nos plantea serias dudas respecto a su oportunidad, ello sin restar mérito a la propuesta que, por lo demás, resulta muy interesante, sobre todo por el hecho de plantearse como alternativa a los actuales y molestos baños de lodo en dicha laguna. No obstante esta cuestión y a pesar de las encuestas realizadas a los usuarios del parque, también nos suscita cierto recelo que realmente se consiga sustituir una práctica recreativa, hasta el momento gratuita, por un servicio remunerado.

En concreto, las razones de nuestra reticencia se fundamentan, por una parte, en las propias características del espacio protegido que constituye el parque natural de las lagunas de Torrevieja-La Mata, al tratarse de una zona húmeda cuya fragilidad impone unas limitaciones de uso mayores a las de otros parques naturales. Por otra, la segunda cuestión hace referencia a la situación de partida que presenta este espacio, como ya hemos comentado, afectado por una densa ocupación residencial en su entorno inmediato, con una configuración que deja poco margen de maniobra a las propuestas encaminadas a conciliar desarrollo y conservación, aspecto que recomendaría, en la medida de lo posible, distanciar al máximo todo tipo de construcciones de las lagunas, aunque tuvieran como fundamento el parque. De hecho, la ejecución de este proyecto, además de aumentar la presión humana sobre el ecosistema, disminuiría la calidad visual del paisaje, puesto que acortaría las visuales y contaminaría con elementos artificiales las vistas directas en su entorno inmediato.

13 Solamente consta la superficie -2 hectáreas o incluso superior - que ocuparía la laguna artificial a excavar, con una profundidad máxima de $60 \mathrm{~cm}$. 
Además, en tercer lugar, la iniciativa del balneario de lodos no parece ajustarse a las actuaciones de pequeña escala apropiadas para estos espacios naturales $\mathrm{y}$, muy probablemente, acabaría por favorecer el aprovechamiento del parque como una externalidad en beneficio particular - de hecho, ya se ha planteado, por parte de una empresa privada su interés de construir un hotel de cinco estrellas junto al balneario-.

En resumen, dada la fragilidad de esta zona húmeda, las consideraciones expuestas en relación con la zonificación y distribución de las infraestructuras y equipamientos en su interior y en su perímetro de protección, cuestionan en parte el modelo de ordenación propuesto. Sobre todo porque algunas de estas actuaciones no tienen mucha conexión con el uso público de los ENP y sus objetivos de información, observación, interpretación y educación, relacionándose con una finalidad meramente lúdica sin interés por el disfrute de la naturaleza, a lo que se añade la falta de evaluación del impacto que su construcción y acondicionamiento generará.

Más aún, la actividad planteada, inserta en la problemática de las relaciones entre conservación y desarrollo, respecto a la demanda social de espacios naturales y a las funciones que cumplen, en razón a los servicios ambientales que prestan a la sociedad y a su papel como soporte de actividades económicas, podría entrar en contradicción con otro tipo de demanda que prima sus funciones ecológicas por encima de su capacidad como recurso productivo (AZQUETA, 2001). Observación por tanto de la máxima importancia, a tener en cuenta en la planificación del uso público de los espacios naturales protegidos. Un uso público que, dadas sus características, debe estar ligado a sus valores ambientales, tal como se expone en el documento Loving them to death?, editado por la Federación Europarc. Por tanto, ante cualquier iniciativa del tipo contemplado, se ha de imponer como condición sine qua non el garantizar la conservación del espacio natural protegido.

De igual manera y como otro problema a comentar, en el conjunto de los documentos que integran el plan, no se atiende en profundidad a la inserción de este espacio natural en su contexto socioterritorial ya que, si bien se alude a la situación del mismo en un entorno urbanizado, sólo se hace referencia al municipio de Torrevieja, sin abarcar los municipios vecinos asimismo incluidos en el área de influencia del parque. Por lo tanto, aparte de lo que supone obviar este tipo de estudio para la mejor conservación y ordenación del paraje - sobre todo si recordamos la inexistencia de PORN-, tampoco se tienen en cuenta todas sus posibilidades de articulación y desarrollo territorial en un ámbito más amplio de carácter comarcal, tal como hubiera sido conveniente. De hecho, aunque se trate de un POUP referido a un espacio determinado, con unos límites geográficos establecidos por la administración, no se puede olvidar que mantiene unas relaciones con su entorno inmediato que es preciso considerar. En este sentido, sería interesante plantearse la posibilidad de elaborar un Plan de Acción Territorial de carácter integrado referido a la protección y ordenación del uso público del conjunto de espacios naturales protegidos, de forma tal que el POUP se encargara de concretar sus previsiones y de programar su puesta en marcha respecto al parque natural. De todos modos, la carencia de este tipo de planes aconseja elaborar un POUP que tuviera en cuenta tanto los parques naturales aledaños, es decir, los espacios que cuentan también con la misma figura legal de protección, sobre todo en atención al tipo común de hábitat que ofrecen, como de otros que, sin disponer de tal distintivo, albergan también sobrados valores ecológicos, estando algunos de ellos incluidos en la propuesta de Lugares de Interés Comunitario que configurarán la futura Red Natura 2000.

A la vez, la importancia de incluir estos espacios y no restringirse al ámbito inmediato al parque natural de las lagunas, permitiría una distribución más racional de los equipamientos e infraestructuras, así como la prolongación de los itinerarios, todo lo cual benefi- 
ciaría el tejido socioeconómico de una zona más amplia, resultando así también mayores posibilidades para su diferenciación en cuanto destino turístico. De este modo, el POUP podría servir de base para promover otras iniciativas tanto de carácter público como privado, en relación con el disfrute y uso público del conjunto de espacios naturales de la zona, idea que también se sostiene en el Plan de Acción para los Espacios Naturales Protegidos del Estado Español - pero sin reducirse exclusivamente a actuaciones literalmente «pegadas» a su perímetro. Este documento al considerar el turismo como posible actividad a introducir en estas zonas, asume los principios de la Carta Europea del Turismo Sostenible en Espacios Protegidos (EUROPARC, 1998), y remite al desarrollo de un producto turístico de calidad y respetuoso con el medio ambiente, que favorezca el descubrimiento y la interpretación del patrimonio, sin olvidar la educación ambiental.

En conclusión, se aconseja emprender, una planificación más ajustada a las propias características del parque natural, capaz de resolver acertadamente la relación entre conservación y uso público respecto a las demandas recreativas, sobre todo ante la ausencia de una adecuada política de espacios de ocio en el medio natural capaz de atenderlas (BLÁZQUEZ, 1999). Prima, asimismo, efectuar un análisis del contexto territorial en el que se inserta este ENP, para considerar todas las relaciones con su entorno, de manera que las nuevas funciones del parque natural repercutan en el sistema socioeconómico comarcal y, en particular, se aprovechen las oportunidades que brinda su existencia para promover un desarrollo turístico acorde con su conservación y, por tanto, sostenible, proyecto que además se podría adherir a la citada Carta Europea del Turismo Sostenible en los Espacios Protegidos, con el consiguiente compromiso de cumplir todos sus principios. En este sentido, el parque natural podría fundamentar el diseño de productos turísticos basados en la valoración de sus propios recursos, en los que se podría incluir la oferta de los espacios de valor ambiental cercanos (Salinas de Santa Pola, El Hondo, Dunas de Guardamar, Sierra de Escalona, etc.), favoreciendo, incluso, la creación de alojamientos en albergues, bien en otro tipo de establecimientos. Por último, cabe destacar que la revisión anunciada de los PRUG de los tres parques naturales localizados en el extremo sur de la provincia de Alicante, con la intención de aplicar un tratamiento conjunto e integral para la ordenación de sus perímetros de protección, se podría aprovechar como punto de partida para elaborar una planificación de mayor alcance territorial. En definitiva, lo más deseable sería que la existencia de estos espacios redundara en el desarrollo socioeconómico de las zonas aledañas, pero no a costa de su propio sacrificio y destrucción.

\section{Bibliografía}

BAÑOS CASTIÑEIRA, C. J. (1998) : «La oferta turística complementaria en los destinos turísticos alicantinos: implicaciones territoriales y opciones de diversificación», en Investigaciones Geográficas, $\mathrm{n}^{\circ} 19$, pp. 85-103.

AZQUETA, D. (2001): «La demanda social de los espacios naturales», en BUENDÍA AZORÍN, J.D. y COLINO SUEIRAS, J. (Edts.): Turismo y Medio Ambiente. Cívitas. Madrid. pp. 51-68.

BLÁZQUEZ I SALOM, M. (1999): «Recreo al aire libre y conservación de la naturaleza en Europa occidental», en Ería, no 49. pp. 203-211.

DE LA VEGA, A. (Coord.) (2000): Guía Práctica de Aves del Parque Natural de las lagunas de La Mata y Torrevieja. Ayuntamiento de Torrevieja. Alicante.

EUROPARC-España (2002): Plan de Acción para los Espacios Naturales Protegidos del Estado Español. Fundación Fernando González Bernáldez. Madrid.

FERNÁNDEZ TABALES, A. y SANTOS PAVÓN, E. (1999): «Turismo y uso público en los espacios protegidos andaluces. El estado de la cuestión a los diez años de la aprobación de la Ley de Espacios Naturales Protegidos de Andalucía», en Actas del XVI Congreso de la Asociación de 
Geógrafos Españoles: El territorio y su imagen. Departamento de Geografía de la Universidad de Málaga. Málaga. pp. 439-448.

Fundación Cavanilles de Altos Estudios Turísticos (1995): Bases para la redacción del Plan Director de los Espacios Turísticos de la Comunidad Valenciana. Alicante.

GARAYO URRUELA, J. M. (2001): «Los espacios naturales protegidos: entre la conservación y el desarrollo», en Lurralde (Investigación y Espacio), nº 24. pp. 271-293.

GENERALITAT VALENCIANA (1995): El uso del suelo en la Comunidad Valenciana. Documento III del Avance del PDU. COPUT. Valencia.

GOYTIA PRAT, A. (1999): «Nuevas tendencias de ocio y turismo», en Papers de Turisme, $\mathrm{n}^{\circ} 23$, pp. 89-97.

HEUKEMES, N. (Dir.) (1993): Loving them to death? Sustainable tourism in Europe's Nature and National Parks. Federación de Parques Naturales y Nacionales de Europa.

Instituto de Ciencias Sociales y Ambientales (1997): Proyecto de Plan de Ordenación del Uso Público del Parque Natural de las Lagunas de Torrevieja y La Mata. Murcia.

LACOSTA ARAGÜÉS, A. J. (1997): «Aprovechamiento turístico y conservación del patrimonio natural y cultural en los parques naturales regionales franceses. El caso del parque de Lorena». Geographicalia, nº35 . Diciembre. pp. 129-148.

LAURENS, L. y COUSSEAU, B. (2000): «La valorisation du tourisme dans les espaces protégés européens: quelles orientations possibles?, en Annales de Géographie, $\mathrm{n}^{\circ}$ 613. pp. 240-258.

PLAZA GUTIÉRREZ, J. I. (1999): «Espacios naturales, territorio y desarrollo. (Reflexiones teóricas y sobre formas de gestión. Algunos ejemplo de la región castellano-leonesa)», en VALLE BUENESTADO, B. (Coord.): Geografía y espacios protegidos. AGE y Federación de Espacios Naturales Protegidos de Andalucía. Murcia. pp. 311-331.

SUCH CLIMENT, M.P. (1996): Turismo y medio ambiente en el litoral alicantino. Instituto de Estudios Juan Gil-Albert. Alicante. 296 pp.

SUCH CLIMENT, M.P. (2000): Turismo y medio ambiente en la Comunidad Valenciana. Dpto. Análisis Geográfico Regional. Universidad de Alicante. Tesis doctoral inédita.

TORRES ALFOSEA, F.J. (1995): Aplicación de un sistema de información geográfica al estudio de un modelo de desarrollo local. Crecimiento urbano-turístico de Torrevieja (1956-1993). Universidad de Alicante. Murcia. 103 pp.

VERA REBOLLO, J.F. (1987): Turismo y urbanización en el litoral alicantino. Instituto de Cultura Juan Gil-Albert. Alicante. 441 pp.

VERA REBOLLO, J. F. y MONTFORT MIR, V. (1994) «Agotamiento de modelos turísticos clásicos. Una estrategia territorial para la cualificación: la experiencia de la Comunidad Valenciana», en Estudios Turísticos, $\mathrm{n}^{\circ}$ 123. pp. 17-45.

VERA REBOLLO, J.F. et al. (1996): «Turismo y organización del territorio», en Cuadernos de Geografía, no 58 , pp. 439-474.

VERA REBOLLO, J.F. (Coord.) (1997): Análisis Territorial del Turismo. Ariel Geografía. Barcelona. 
